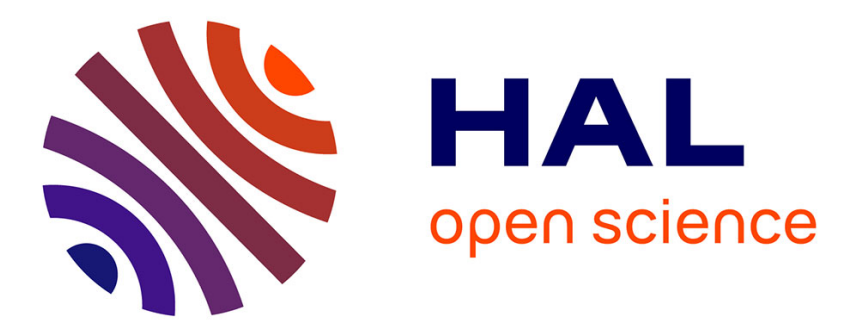

\title{
Shipping noise in whale habitat: Characteristics, sources, budget, and impact on belugas in Saguenay-St. Lawrence Marine Park hub
}

Cedric Gervaise, Yvan Simard, Nathalie Roy, Bazile Kinda, Nadia Menard

\section{To cite this version:}

Cedric Gervaise, Yvan Simard, Nathalie Roy, Bazile Kinda, Nadia Menard. Shipping noise in whale habitat: Characteristics, sources, budget, and impact on belugas in Saguenay-St. Lawrence Marine Park hub. Journal of the Acoustical Society of America, 2012, 132 (1), pp.76-89. 10.1121/1.4728190 . hal-00857183

\section{HAL Id: hal-00857183 \\ https://hal.science/hal-00857183}

Submitted on 3 Sep 2013

HAL is a multi-disciplinary open access archive for the deposit and dissemination of scientific research documents, whether they are published or not. The documents may come from teaching and research institutions in France or abroad, or from public or private research centers.
L'archive ouverte pluridisciplinaire HAL, est destinée au dépôt et à la diffusion de documents scientifiques de niveau recherche, publiés ou non, émanant des établissements d'enseignement et de recherche français ou étrangers, des laboratoires publics ou privés. 


\title{
Shipping noise in whale habitat: Characteristics, sources, budget, and impact on belugas in Saguenay-St. Lawrence Marine Park hub
}

\author{
Cédric Gervaise \\ GIPSA-Lab, Dept. Image-Signal, 11 rue des Mathématiques, 38402 Saint-Martin d'Hères, France \\ Yvan Simard ${ }^{\text {a) }}$ and Nathalie Roy \\ Maurice Lamontagne Institute, Fisheries and Oceans Canada, 850 route de la Mer, Mont-Joli, \\ Québec G5H-3Z4, Canada \\ Bazile Kinda \\ STIC AP, ENSTA-Bretagne, 2 rue François Verny, 29200, Brest, France \\ Nadia Ménard
Saguenay-St. Lawrence Marine Park, Parks Canada, 182 rue de l'Église, P.O. Box 220, Tadoussac,
Québec GOT 2A0, Canada
}

(Received 25 October 2011; revised 14 May 2012; accepted 22 May 2012)

A continuous car ferry line crossing the Saguenay Fjord mouth and traffic from the local whale-watching fleet introduce high levels of shipping noise in the heart of the Saguenay-St. Lawrence Marine Park. To characterize this noise and examine its potential impact on belugas, a 4-hydrophone array was deployed in the area and continuously recorded for five weeks in May-June 2009. The source levels of the different vessel types showed little dependence on vessel size or speed increase. Their spectral range covered $33 \mathrm{~dB}$. Lowest noise levels occurred at night, when ferry crossing pace was reduced, and daytime noise peaked during whale-watching tour departures and arrivals. Natural ambient noise prevailed $9.4 \%$ of the time. Ferry traffic added $30-35 \mathrm{~dB}$ to ambient levels above $1 \mathrm{kHz}$ during crossings, which contributed 8 to $14 \mathrm{~dB}$ to hourly averages. The whale-watching fleet added up to $5.6 \mathrm{~dB}$ during peak hours. Assuming no behavioral or auditory compensation, half of the time, beluga potential communication range was reduced to less than $\sim 30 \%$ of its expected value under natural noise conditions, and to less than $\sim 15 \%$ for one quarter of the time, with little dependence on call frequency. The echolocation band for this population of belugas was also affected by the shipping noise.

[http://dx.doi.org/10.1121/1.4728190]

PACS number(s): 43.30.Nb, 43.50.Rq, 43.80.Pe [JJF]

Pages: 76-89

\section{INTRODUCTION}

The effect of anthropogenic noise on marine life is a worldwide concern that has been the object of several reviews recently (Southall et al., 2007; Popper and Hastings, 2009; Boyd et al., 2011). Global energy budgets clearly point at shipping as the main contributor to this noise (Hildebrand, 2009). The risk of significant impact increases in high-traffic areas such as choke points along busy shipping lines and converging traffic around ports, where this type of continuous noise peaks, especially when this overlaps with sensitive habitats of marine wildlife, where vital functions such as feeding, breeding, or nurturing take place.

Several studies have reported behavioral reactions of marine mammals to the presence of whale-watching boats (Foote et al., 2004; Holt et al., 2009; Lusseau et al., 2009). However, only some of them have measured the actual

\footnotetext{
a) Author to whom correspondence should be addressed. Also at: Marine Science Institute, University of Québec at Rimouski, 310 Allée des Ursulines, Rimouski, Québec G5L-3A1, Canada. Electronic mail: yvan_simard@ uqar.qc.ca
}

source levels (SLs) emitted by the boats or the probability distribution of noise levels encountered in these high-traffic areas (Erbe, 2002; Kipple and Gabriele, 2003, 2004; Holt et al., 2009; Jensen et al., 2009). Noise radiated by a fleet composed of a mixture of ships and boats of variable sizes is expected to cover a wide range of frequencies, from infrasound of a few $\mathrm{Hz}$ to ultrasound exceeding $20 \mathrm{kHz}$ (Arveson and Vendittis, 2000; Erbe, 2002; Kipple and Gabriele, 2003, 2004; NRC, 2003). Such a broad band covers the hearing sensitivity and communication bands of several marine organisms, especially marine mammals, and can reach the high-frequency echolocation bands used by toothed whales to navigate underwater and detect their preys with clicks and buzzes (Au and Hastings, 2008).

The mouth of the Saguenay Fjord in Lower St. Lawrence Estuary in Eastern Canada is one such high-traffic sensitive area of the Saguenay-St. Lawrence Marine Park (SSLMP) which is regularly frequented by marine mammals (Fig. 1). The traffic is originating from the Saguenay car ferry line that bridges the main road over the $1.4-\mathrm{km}$ wide fjord [Fig. 1(c)], the whale watching fleet operating from May to October from Tadoussac and Baie Sainte-Catherine 

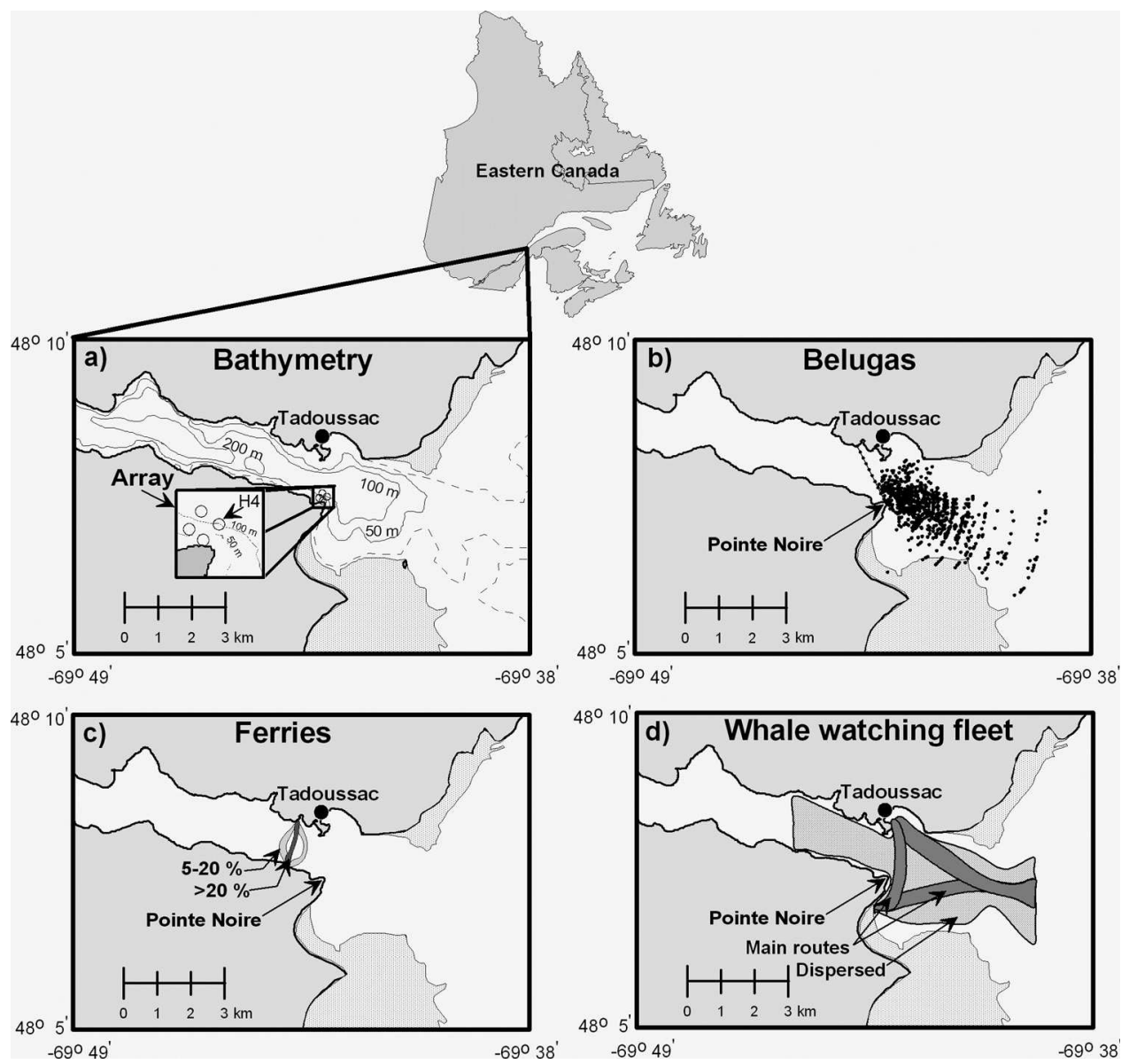

FIG. 1. Map of Saguenay Fjord mouth showing (a) the bathymetry of the study area, (b) the locations of beluga groups from daytime reticule binocular observations from Pointe Noire during the study period, (c) the Saguenay ferries main paths as described by Chion et al. (2010) from AIS data analysis, and (d) the distribution of monitored whale-watching boats in summer 2009 from Parks Canada vessel track observations.

ports on each side of the fjord [Fig. 1(d)] and from occasional summer yachting, and cargo ships including large cabin cruisers (Chion et al., 2010). The daily traffic is rhythmed with the Saguenay ferries schedule and the whalewatching fleet departure and arrivals, which tend to match the meal times (Table I) (Chion et al., 2010). Short periods of no traffic and low noise occur during night, when the single servicing ferry is docked and waiting for the next scheduled crossing. This diel traffic pattern offers the advantageous possibility of estimating the separate contribution of the different sources to the soundscape and assessing the local level of the natural ambient ${ }^{1}$ noise because the local basin is relatively well isolated by the extensive Saguenay Fjord sill from other distant shipping noise sources in the St. Lawrence adjacent basin where St. Lawrence Seaway traffic is transiting.

Tadoussac is a worldwide renowned whale-watching destination where hundreds of thousands of ecotourists embark on boat tours to observe several species of whales foraging in SSLMP nearby Laurentian channel head in Lower St. Lawrence Estuary during summer (O'Connor et al., 2009). The Saguenay Fjord mouth is mainly frequented by

TABLE I. Saguenay ferry shipping and whale-watching fleet diel schedule. Measured broadband $\mathrm{SPL}_{[1-20 \mathrm{kHz}]}$ (in dB re $1 \mu$ Pa) and estimated natural ambient and ferry noise levels averaged over $1 \mathrm{~h}$.

\begin{tabular}{|c|c|c|c|c|c|}
\hline \multirow{2}{*}{\multicolumn{2}{|c|}{ Sources }} & \multicolumn{4}{|c|}{ Period of the day (h) } \\
\hline & & midnight -4 am & $4 \mathrm{am}-8$ am and $11 \mathrm{am}-$ midnight & $8 \mathrm{am}-9: 00 \mathrm{pm}$ & $10: 30 \mathrm{am}-4: 30 \mathrm{pm}^{\mathrm{a}}$ \\
\hline \multirow[t]{3}{*}{ Ferries } & no. & 1 & 1 & 2 & 3 \\
\hline & No. of transits $h^{-1}$ & 2 & 3 & $3 \times 2$ & $5 \times 2$ \\
\hline & Noise level $[1-20 \mathrm{kHz}]$ & 102.1 & 104.0 & 107.0 & 110.9 \\
\hline \multirow{2}{*}{\multicolumn{2}{|c|}{ Whale-watching tour departures and arrivals times ${ }^{\mathrm{b}}$}} & & & $\begin{array}{l}9,12,13 \\
3: 30 \mathrm{pm}\end{array}$ & \\
\hline & & - & - & $4: 30 \mathrm{pm}, 6 \mathrm{pm}$ & - \\
\hline Total no & $20 \mathrm{kHz}]$ & 102.1 & 104.0 & $107.0-112.6$ & - \\
\hline \multicolumn{6}{|c|}{ Natural ambient } \\
\hline Noise & $\mathrm{kHz}]$ & 95.9 & 95.9 & 95.9 & 95.9 \\
\hline
\end{tabular}

${ }^{\mathrm{a}}$ From mid-June to Sept.

${ }^{\mathrm{b}}$ Summer estimates from Chion et al. (2010). 
belugas (or white whales, Delphinapterus leucas), especially during the flood (SSLMP unpublished data; Simard et al., 2010). Minke whales, harbor seals, gray seals, and, occasionally, fin and humpback whales also frequent the area. Belugas are known to make extensive use of acoustics for communication and echolocation. Their main calling frequency band is between 0.5 and $5 \mathrm{kHz}$ (Bédard and Simard, 2006) while their echolocation clicks are generally above $30 \mathrm{kHz}(\mathrm{Au}$ et al., 1985; Roy et al., 2010).

Field experiments in the St. Lawrence have concluded that boat and ship noises can interfere with beluga communication and induce responses by changing the frequency, level, rate, and repetition of the calls (Lesage et al., 1999; Scheifele et al., 2005). High shipping noise levels thus risk to interfere with their normal behavior, induce masking (Erbe and Farmer, 1998; Erbe, 2008), and significantly reduce communication ranges, as noted for baleen whale low-frequency calls in St. Lawrence Estuary and in other whale habitats crossed by busy seaways (Simard et al., 2008; Clark et al., 2009).

The objective of this paper is to characterize the soundscape of this high-traffic area of the SSLMP that is intensively used by belugas for foraging as well as for their transits between other highly used habitats within the Saguenay Fjord or the St. Lawrence Estuary (Roy et al., 2010; Simard et al., 2010), for a significant 5-week continuous period, over a large frequency bandwidth. Specifically, this study wants to characterize this anthropogenic noise and to determine: (i) the soundscape budget, (ii) the changes in levels with the diel changes in ferry and whale-watching traffic, (iii) the relative contributions of the natural ambient background, the local ferry line and the whale-watching fleet, (iv) the spectral source levels (SSL) of the various types of whale-watching vessels, (v) the effect of their cruising speed, and (vi) the impact of this anthropogenic noise on the potential communication range of belugas compared to natural noise conditions.

The next sections first present the acoustic observatory deployed in the Saguenay Fjord mouth basin, the vessel speed experiment protocol, and the methods used for estimating soundscape statistical characteristics. The results and discussion are then presented in three sections: (1) the SL characteristics of the main vessel types composing the local fleet, (2) the soundscape analysis, and (3) the impact on beluga communication space. Management considerations for local noise mitigation are pointed out, and perspectives for further work for assessing the spatial-temporal impact of local shipping noise on whale communications and echolocation are discussed.

\section{MATERIAL AND METHODS}

\section{A. Study area characteristics}

The study area is the $\sim 5-\mathrm{km}$ long segment of the mouth of the Saguenay Fjord, upstream of its outer sill extending in the Lower St. Lawrence Estuary (Fig. 1). The fjord width there varies from 1 to $3 \mathrm{~km}$. Its maximum depth reaches 150-200 m. The fjord is carved in the Canadian shield rock and its basin is separated from that of the St. Lawrence by an extensive $\sim 10-\mathrm{km}$ long morainic sill complex, where a 1-km wide channel shoals at a minimum depth of $20 \mathrm{~m}$. The entrance basin is further isolated from the St. Lawrence Estuary by two flats emerging at low water on either side of the mouth. The bottom type in the basin is compacted sand and gravel in the deep bottom and on the sill slope, and gneiss rock on the fjord walls.

The fjord discharges a 10-15 m thick surface water mass of brackish water reaching salinities of 7-22 PSU (practical salinity units) and temperatures of $5-7^{\circ} \mathrm{C}$ in the study area. Below the thermo-halocline, the water mass originates from the cold intermediate layer $\left(1.5-2.0^{\circ} \mathrm{C}\right.$ and $\left.27-28 \mathrm{PSU}\right)$ of the Lower St. Lawrence Estuary, which upwells over the sill during flood tides and subducts below the upper layer, generating a sharp tidal front at the subduction zone.

The sound speed profile is therefore varying with the tidal cycle and the along-fjord location relative to the subduction front. The sound speed profile was obtained from conductivity, temperature and depth (CTD) casts made at the beginning and the end of the recording session. On average the mean sound speed varies from $1443 \mathrm{~m} \mathrm{~s}^{-1}$ to $1453 \mathrm{~m} \mathrm{~s}^{-1}$ and the profile has a minimum at a depth of $\sim 100 \mathrm{~m}$. Shipping traffic statistics were made available by SSLMP from a study conducted in 2007 (Chion et al., 2007).

Time series of wind speed during the observation period were recorded at an hourly rate by the Environment Canada weather station at Pointe de l'Islet, just off the hydrophone array on the Tadoussac side. Wind speeds during the recording period averaged $12.4 \pm 6.8^{2} \mathrm{kn}$.

\section{B. Acoustic observatory}

The acoustic recordings were collected from May 4 to June 10, 2009 at Pointe-Noire (Fig. 1) where a cabled coastal array of four omnidirectional HTI 96 MIN hydrophones (High Tech Inc., Gulfport, MS) was set up. The 4-hydrophone array was deployed with two cables plunging into the mid-water column along the cape [Fig. 1(a)]. The deployment aimed at forming a $\sim 250-\mathrm{m}$ square array tilted along the bottom half of the slope, between 30 and $140 \mathrm{~m}$. The hydrophones were kept about $4 \mathrm{~m}$ above the bottom by a small float and a thin wooden stick wrapped around the cable. Their approximate locations were determined from the global positioning system (GPS) positions of the launching points of the cables and hydrophones during the array deployment from the Canadian Coast Guard Fisheries Research Vessel Calanus II. More precise hydrophone positions were calculated from acoustic localization using known sources emitted from the ship at eight different positions around the array and a sound speed profile obtained from a CTD (SBE 19, Seabird Electronics, Bellevue, WA) cast made in the array region. The final array aperture was about $230 \mathrm{~m}$. On the shore, the cables were connected to a lownoise custom amplifier $(+25 \mathrm{~dB})$ before feeding a data acquisition board (IOtech DaqBoard 3000/USB, Cleveland, $\mathrm{OH})$ connected to a personal computer which digitized the signal on 16 bits at either 48 or $200 \mathrm{kHz}$ for each hydrophone. The data were stored in wav (waveform audio file) formats on external hard disks. The hydrophone receiving sensitivity (RS) vs frequency was calibrated at the Defence 
Research and Development Canada facility (Dartmouth, NS) over the $50 \mathrm{~Hz}-20 \mathrm{kHz}$ frequency band. The observatory gathered 1.3 TB of acoustic data during the 5-week recording session, which excludes a three-day period without recordings due to material breakdown.

\section{Data analysis}

\section{Estimation of noise levels}

Raw data were transformed to instantaneous pressure in $\mu \mathrm{Pa}$ using the analog-to-digital conversion factor, amplification gain, and hydrophone RS curves. Narrow band spectral levels (PSD, in $\mathrm{dB}$ re $1 \mu \mathrm{Pa}^{2} \mathrm{~Hz}^{-1}$ ) from $10 \mathrm{~Hz}$ to $20 \mathrm{kHz}$ were estimated using the fast Fourier transform algorithm with a rectangular window, $L$, of 24000 samples with $50 \%$ overlap, providing a frequency resolution of $\sim 2 \mathrm{~Hz}$ and a time resolution of $250 \mathrm{~ms}$. Wideband sound pressure levels $\left(\mathrm{SPL}_{\mathrm{wb}}\right.$, in $\mathrm{dB}$ re $\left.1 \mu \mathrm{Pa}\right)$ in the bandwidths $B=\left[f_{1}, f_{2}\right]$ were computed for two adjacent bandwidths of interest, $B 1$ $=[0.01-1 \mathrm{kHz}]$ and $B 2=[1-20 \mathrm{kHz}]$.

\section{Estimation of soundscape statistical characteristics}

The PSD and SPL $\mathrm{wb}_{\mathrm{wb}}$ time series were computed with the above time step resolution for the entire duration of the recordings. Noise level was thus characterized at each $t(k)$ time step by quantities $Q(k)$, such as $\operatorname{PSD}(t(k), f)$ and $\operatorname{SPL}_{\mathrm{wb}}(t(k), B 1$ or $B 2)$. The 40-day recording session generated $162 \times 10^{6}$ samples of $Q(k)$, which were used to estimate the probability density function (pdf) of $Q, \operatorname{pdf}_{Q}(\alpha)$, its cumulative density function (cdf), $\operatorname{cdf}_{Q}(\alpha)$, and to derive its statistical moments such as the mean, standard deviation, median, or percentiles. Statistics were computed on the estimated dB levels.

The noise conditions during daytime ( $D$, heavy traffic) and nighttime ( $N$, weak traffic) were compared using the following statistical framework. To evaluate the changes in noise levels between daytime and nighttime, one can look at the difference in PSD or SPL $\mathrm{wb}_{\mathrm{wb}}$ levels corresponding to the same percentiles of their respective pdf. One can also compute the probability that daytime noise differs from nighttime noise by $\eta \mathrm{dB}$. To do so, we first define the difference $\delta$ (dB) between daytime and nighttime conditions $(D-N)$ and we compute its cdf and pdf as follows:

$$
\begin{aligned}
& c d f_{\delta}(\eta)=\int_{\alpha}\left(1-c d f_{D}(\alpha-\eta)\right) p d f_{N}(\alpha) d \alpha, \\
& p d f_{\delta}\left(\eta_{0}\right)=\frac{\partial c d f_{\delta}}{\partial \eta}\left(\eta_{0}\right) .
\end{aligned}
$$

As indicated above for $Q$, the statistics of $\delta$ were computed from $\operatorname{cdf}_{\delta}(\eta)$ and $\operatorname{pdf}_{\delta}(\eta)$.

\section{Excess from natural ambient noise and masking impact}

Natural noise levels ( $\mathrm{SPL}_{\text {nature }}$ ) were estimated as the percentiles of the pdfs of $\mathrm{SPL}_{\mathrm{wb}}$ or PSD that correspond to the observed mean level during nighttime low-traffic conditions from which the estimated contribution of the
Saguenay ferry has been removed (see Sec. IV). The statistical properties of the increment of the noise level relative to natural levels, $\Delta N L$, were obtained from the same statistical approach described previously for $\delta$.

The effect this shipping noise has on reducing beluga and other whales' potential communication range can be assessed as follows. Assuming spherical spreading losses and no behavioral or auditory response to increasing noise levels from the belugas, the range reduction factor, RRF, for a given spectral noise level, PSD, relative to an ideal case corresponding to natural noise levels, can be computed from

$$
R R F_{P S D}=10^{-\left(\mathrm{PSD}-\mathrm{PSD}_{\text {nature }}\right) / 20}
$$

This is valid only when the PSDs + critical ratio (see Sec. IV) are exceeding the auditory threshold. The cdf of $\mathrm{RRF}_{\mathrm{PSD}}$ was computed to assess the statistical characteristics of the reduction in whales' potential communication range as a function of the calling frequency. The same reasoning can be applied to estimate the RRF for echolocation but with 40 as the divisor of the exponent in Eq. (2), to account for the two-way spherical spreading loss along the transmitted and received paths between the beluga and the target.

\section{Estimation of vessel type SLS}

A three-day experiment was dedicated to study the noise radiated by the main vessel types composing the whalewatching fleet. Twelve representative vessels were chosen among the fleet (Table II). Each ship was asked to cruise along a predefined $1-\mathrm{km}$ long strait track at $400 \mathrm{~m}$ from Pointe-Noire in front of the acoustic observatory, at two different speeds ranging from 10 to $25 \mathrm{kn}$.

The precise vessel trajectory and speed over ground (SOG) were obtained from on-board GPS. For any pair of vessel and hydrophone, the recordings corresponding to the GPS tracks were extracted as well as the position, time, and SOG at the closest point of approach (CPA). A local oceanic tidal circulation model (Fisheries and Oceans Canada, Maurice-Lamontagne Institute, Mont-Joli, QC, Canada) was run to estimate the actual current speed at the times of the vessel tracks. The SOGs were then corrected by the estimated surface current speeds to get the speeds-over-water, which are more relevant for assessing the effect of vessel speed on radiated noise levels.

TABLE II. Characteristics of the whale-watching fleet vessel types used for source level assessment at two sailing speeds.

\begin{tabular}{lccc}
\hline \hline Descriptor & Small & Medium & Large \\
\hline No. of boats measured & 7 & 2 & 3 \\
Length range (m) & $6-12.2$ & $11.2-14.6$ & $23-40.2$ \\
Draft (m) & $0.5-1$ & $1-1.4$ & $1.6-2.2$ \\
Propulsion range (hp) & $1 \times 100-2 \times 370$ & $2 \times 260-2 \times 660$ & $2 \times 375-3 \times 500$ \\
Maximum no. of & & & \\
passengers & $12-48$ & 10 & $250-700$ \\
Cruising speed range & & & $10-15$ \\
(kn) & $20-25$ & 25 & 5 \\
No. of tracks & 21 & 7 & \\
\hline \hline
\end{tabular}


A 30-s recording segment around the time of CPA to the two deepest hydrophones (nos. 3 and 4) was selected for each vessel track. If $p(t)$ is the received pressure at the hydrophone, then an estimation of the emitted signal $e(t)$ by the vessel is produced by multiplying $p(t)$ with the distance $r(t)$ between the ship and the hydrophone at time $t$. This compensation assumes spherical transmission losses from the source to the hydrophone. This assumption is valid in our case since the range at the CPA was small and comparable to water depth $(\mathrm{CPA}$ range $=214 \pm 54 \mathrm{~m})$. Vessel SSL (in $\mathrm{dB}$ re $1 \mu \mathrm{Pa}^{2} \mathrm{~Hz}^{-1}$ at $1 \mathrm{~m}$ ), and wideband source levels, $\mathrm{SL}_{\mathrm{wb}}(f 1, f 2$ ) (in $\mathrm{dB}$ re $1 \mu \mathrm{Pa}$ at $1 \mathrm{~m}$ ), were computed by applying the same formulas used for soundscape assessment. The statistical properties of these SL estimates at different speeds were then computed for the whole fleet and by vessel categories.

For assessing the effect of vessel speed between 10 and $25 \mathrm{kn}$ in a common analysis, changes in radiated noise levels from the different vessels were analyzed as a function of speed increment, instead of absolute SLs vs speed, because of the large dispersion of SLs and max speeds within the fleet. For each track $j$ and each vessel $i, \operatorname{SL}_{\mathrm{wb}}(i, j)$ was computed to estimate the relative SL increment, $\Delta \mathrm{SL}_{\mathrm{wb}}(\mathrm{dB})$, resulting from a relative increment of vessel speed, $\Delta v$ (knots), with

$$
\Delta \mathrm{SL}_{\mathrm{wb}}(i, j)=\mathrm{SL}_{\mathrm{wb}}(i, j)-\mathrm{SL}_{\mathrm{wb}}(i, 1),
$$

$\Delta v(i, j)=v(i, j)-v(i, 1)$, where $v(i, 1)$ is the slowest track for vessel $i$.

\section{RESULTS}

\section{A. Whale-watching fleet SLs}

The cdf percentiles of the whale-watching fleet SSL indicate that higher values are reached at low frequencies,

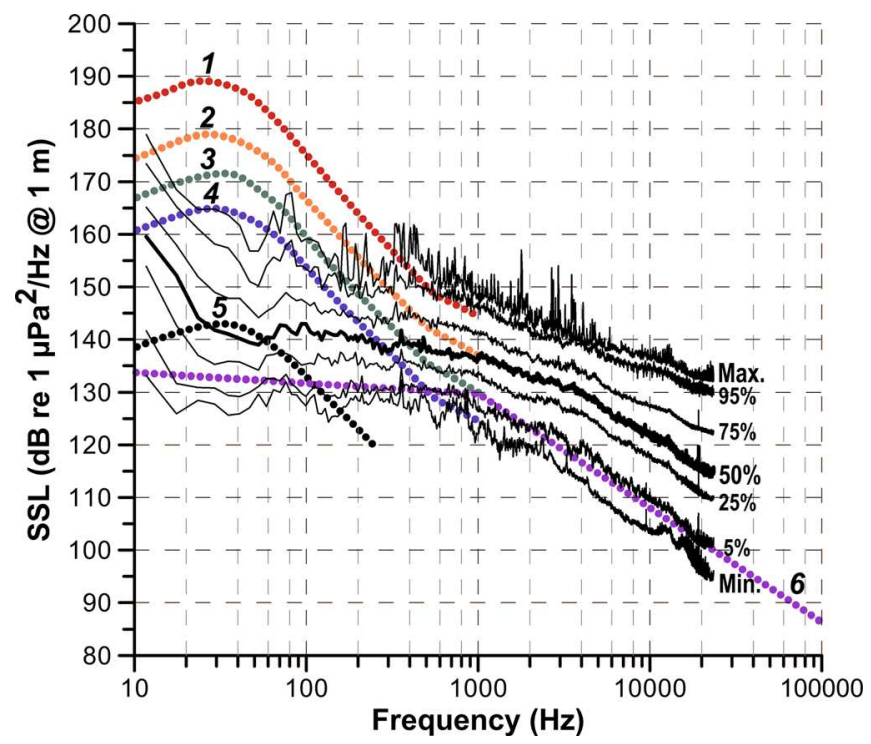

FIG. 2. (Color online) Percentiles of the cdf of the estimated SSL of the whale-watching fleet (continuous lines) and ship SSL references (from Mitson, 1995; NRC, 2003) (dotted lines). 1: supertanker, 2: large tanker, 3 : tanker, 4: merchant ship, 5: fishing vessel, 6: ICES recommendation for fisheries research vessels. with median levels of $160 \mathrm{~dB}$ re $1 \mu \mathrm{Pa}^{2} \mathrm{~Hz}^{-1}$ at $1 \mathrm{~m}$ at $10 \mathrm{~Hz}$ and $115 \mathrm{~dB}$ re $1 \mu \mathrm{Pa}^{2} \mathrm{~Hz}^{-1}$ at $20 \mathrm{kHz}$ (Fig. 2). Local maxima, characteristic of low frequency cavitation noise (Urick, 1983), were apparent on highest percentiles around $100 \mathrm{~Hz}$. Above $500 \mathrm{~Hz}$, SSL decrease linearly at a rate of $19 \mathrm{~dB}$ per decade for the lower percentiles, $15 \mathrm{~dB}$ per decade for the median and $10 \mathrm{~dB}$ per decade for the higher percentiles. SSL variability within the fleet was high at all frequencies. The SSL envelope spans $32.7 \pm 3.9 \mathrm{~dB}$ and the difference between the first and third quartiles averages 10.2 $\pm 1.7 \mathrm{~dB}$.

The SSL were computed separately by vessel size (Fig. 3). The major differences between the median SSL by vessel category were observed above $200 \mathrm{~Hz}$ [Fig. 3(a)]. On average, large vessel SSL exceeded that of small vessels by $7.4 \pm 2.4 \mathrm{~dB}$ and that of medium vessels by $3.6 \pm 1.2 \mathrm{~dB}$ over the studied bandwidth. Medium vessels SSL exceeded small boats SSL by $3.8 \pm 3 \mathrm{~dB}$. At mid frequencies, between 0.8 and $3 \mathrm{kHz}$, small vessels were noisier than medium
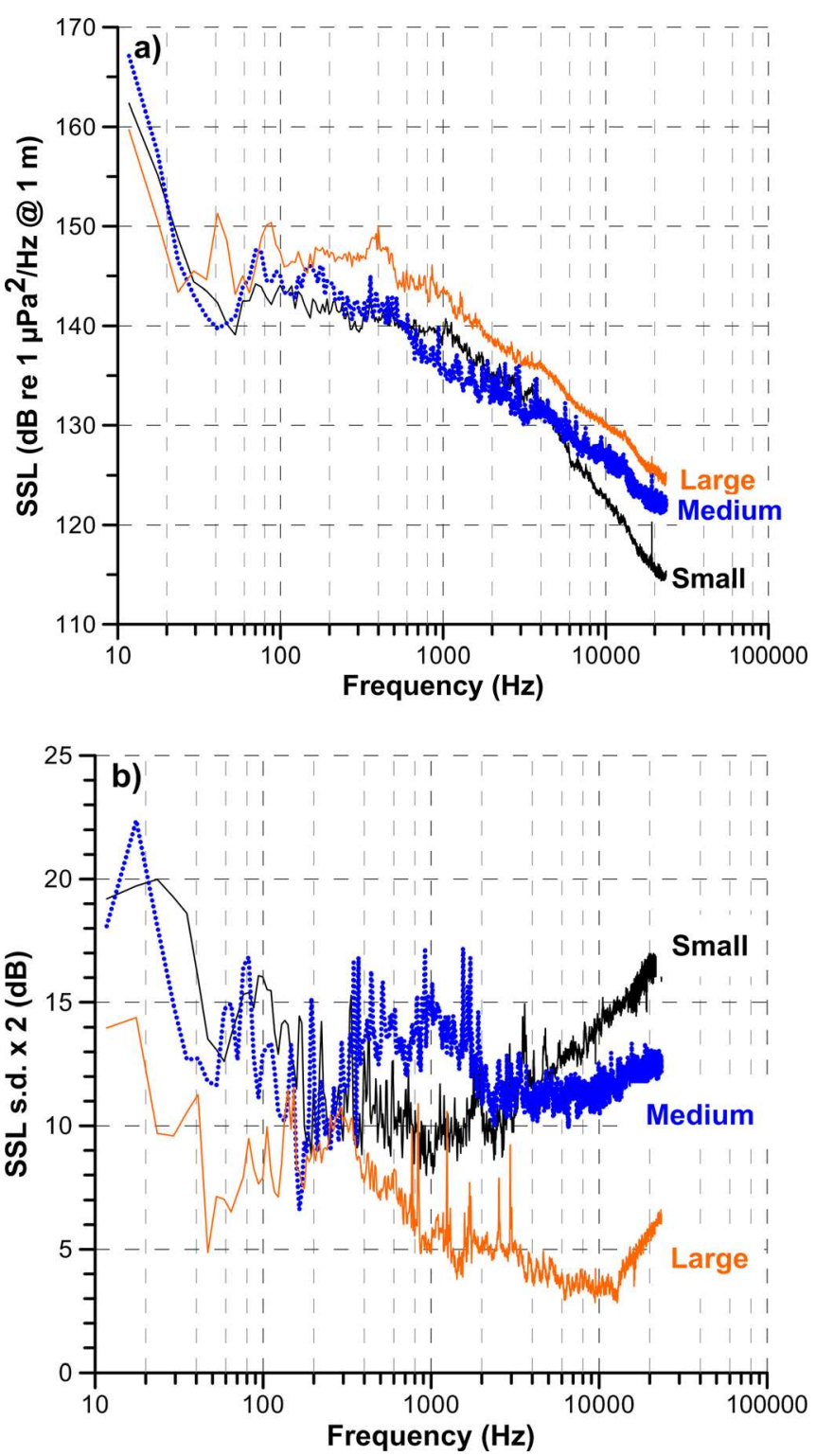

FIG. 3. (Color online) (a) Median SSL per vessel category and (b) their corresponding 2-s.d. envelope. 


\begin{tabular}{|c|c|c|c|c|c|c|c|}
\hline \multirow[b]{3}{*}{ Vessel category } & \multirow[b]{3}{*}{ No. of tracks } & \multicolumn{3}{|c|}{$\mathrm{SL}_{\mathrm{wb}}$ median } & \multicolumn{3}{|c|}{$\mathrm{SL}_{\mathrm{wb}}$ s.d. } \\
\hline & & \multicolumn{3}{|c|}{$(\mathrm{dB}$ re $1 \mu \mathrm{Pa}$ at $1 \mathrm{~m})$} & \multicolumn{3}{|c|}{$(\mathrm{dB})$} \\
\hline & & {$[0.01-1 \mathrm{kHz}]$} & {$[1-20 \mathrm{kHz}]$} & {$[0.01-20 \mathrm{kHz}]$} & {$[0.01-1 \mathrm{kHz}]$} & {$[1-20 \mathrm{kHz}]$} & {$[0.01-20 \mathrm{kHz}]$} \\
\hline All & 131 & 174.8 & 169.9 & 176.0 & 4.7 & 4.9 & 4.2 \\
\hline Small & 83 & 174.6 & 169.2 & 175.7 & 4.8 & 4.8 & 4.3 \\
\hline Medium & 28 & 176.5 & 167.9 & 177.1 & 5.4 & 5.4 & 4.8 \\
\hline Large & 20 & 175.8 & 173.6 & 177.8 & 3.2 & 2.0 & 2.1 \\
\hline
\end{tabular}

vessels, but this was reversed above $3 \mathrm{kHz}$, where medium vessels were noisier. The 2-s.d. (standard deviation) envelopes of SSL increased with decreasing vessel size [Fig. 3(b)], averaging $4.6 \pm 0.9 \mathrm{~dB}$ for large vessels, $12 \pm 0.6 \mathrm{~dB}$ for medium vessels, and $14 \pm 1.5 \mathrm{~dB}$ for small vessels. Wideband SLs computed for bandwidths $B 1$ and $B 2$ illustrate the small differences among vessel types below $1 \mathrm{kHz}$ and the overall 3-dB increase of the mean $\mathrm{SL}_{\mathrm{wb}}$ with vessel size above $1 \mathrm{kHz}$ (Table III).

The influence of speed on SLs was assessed separately for bandwidths $B 1$ and $B 2$ to examine their relative contribution to a possible speed dependence of SL (Fig. 4). At low frequencies the speed increment did not result in clear trends in $\Delta \mathrm{SL}_{\mathrm{wb}}$ [Fig. 4(a)]; noise levels increased for some vessels but decreased for others. The variance was high and larger speed increments corresponded to higher $\Delta \mathrm{SL}_{\mathrm{wb}}$ dispersion. Consequently, the slope of a linear fit was not different from zero $[p=0.305$, Fig. 4(a)]. For the higher frequency band, the variability remained very high $\left(r^{2}=0.4\right)$, but a significant $(p<0.001)$ small increasing trend of $0.5 \mathrm{~dB}$ per incremental knot was observed [Fig. 4(b)]. This slope slightly decreased by pooling the two frequency bands together [Fig. 4(c)]. The dispersion was always very high and the weak relation between $\Delta \mathrm{SL}_{\mathrm{wb}}$ and vessel speed increment never explained more than $40 \%$ of the observed variance $\left(r^{2}<0.4\right)$. Similar slope $(0.44 \mathrm{~dB}$ per incremental knot $)$ and variability $\left(r^{2}=0.42\right)$ can be estimated from data extracted from (Erbe, 2002) [Fig. 4(c)].

\section{B. Characteristics of Saguenay Fjord mouth soundscape}

The median noise PSD over the recording period reached a maximum of $\sim 110 \mathrm{~dB}$ re $1 \mu \mathrm{Pa}^{2} \mathrm{~Hz}^{-1}$ at $10 \mathrm{~Hz}$ and then steadily decreased at $\sim-17.5 \mathrm{~dB}$ per decade with increasing frequency (Fig. 5). Similar decreasing linear trends were observed for lower and higher cdf percentiles, with a fairly constant slope of $-16.6 \pm 1.1 \mathrm{~dB}$ per decade. This linear trend is marked by two $\sim 5-\mathrm{dB}$ humps: the first one between 30 and $100 \mathrm{~Hz}$ and the second one between 1 and $2 \mathrm{kHz}$. The low-frequency hump is visible on all percentiles whereas the $1.5-\mathrm{kHz}$ hump is only visible on the low cdf percentiles. Careful examination of raw data showed that this $1.5-\mathrm{kHz}$ hump is originating from noise arising when the ferries are docked.

The width of the envelope between the 5th and 95th cdf percentiles was nearly constant across the $10 \mathrm{~Hz}$ to $10 \mathrm{kHz}$ frequency band: $38 \mathrm{~dB}$ at $10 \mathrm{~Hz}, 27 \mathrm{~dB}$ at $1 \mathrm{kHz}$ and $32 \mathrm{~dB}$ at $10 \mathrm{kHz}$. The s.d.s of noise PSD are $9.5 \mathrm{~dB}$ at $10 \mathrm{~Hz}, 6.4$ $\mathrm{dB}$ at $1 \mathrm{kHz}$, and $8 \mathrm{~dB}$ at $10 \mathrm{kHz}$. The PSD cdf was nearly Gaussian, as indicated by its symmetry around a centered median, its homogeneous variance over the entire bandwidth, and from $q-q$ plots (cdf of the data vs cdf of a reference Gaussian distribution). This indicates that high noise levels over the entire bandwidth were not from occasional high-level transitory sources, but from persistent intrinsic local sources.

During the night, shipping was low and ambient noise was near natural background levels. This quiet state was interrupted during daytime by the resuming of intense ferry crossings and whale-watching tours. The mean values of $\mathrm{SPL}_{\mathrm{wb}}$ at nighttime (8:00 pm-6:00 am) and daytime (6:00 am-8:00 pm) in bandwidth $B 1$ were $117.9 \mathrm{~dB}$ and 119.6 $\mathrm{dB}$, respectively, whereas they were $102.7 \mathrm{~dB}$ and $107.2 \mathrm{~dB}$, respectively, in the bandwidth $B 2$.

A three-dimensional (3D) table was computed from Eq. (1) to show the probability $\operatorname{pdf}_{\delta}(\eta)$ that daytime noise at a given frequency differs from nighttime noise by $\eta \mathrm{dB}$ (Fig. 6). For any frequency from $10 \mathrm{~Hz}$ to $10 \mathrm{kHz}$, it is more probable that daytime noise exceeds nighttime noise. On average, the difference is $8.4 \pm 0.6 \mathrm{~dB}$. The median difference is $2 \pm 1.7 \mathrm{~dB}$ below $100 \mathrm{~Hz}$ and $5.9 \pm 0.7 \mathrm{~dB}$ above $100 \mathrm{~Hz}$.

The mean broadband SPLs during the recording period clearly showed a diel pattern for both $B 1$ and $B 2$ frequency bands (Fig. 7). The daily means were respectively $119 \pm 1.4$ $\mathrm{dB}$ re $1 \mu \mathrm{Pa}$ at low frequencies and $105.4 \pm 3.0 \mathrm{~dB}$ re $1 \mu \mathrm{Pa}$ at high frequencies. Broadband SPLs were minimal between 10:00 pm and 8:00 am and maximal at 9:30-10:00 am, $12: 00 \mathrm{pm}$, and 1:30 pm. At low frequencies $(B 1)$, lowest values were reached between midnight and 6:00 am (117 \pm 0.8 $\mathrm{dB}$ re $1 \mu \mathrm{Pa}$ ) while highest values were found between 10:00 am and 4:00 pm $(120.7 \pm 0.9 \mathrm{~dB}$ re $1 \mu \mathrm{Pa})$. The difference between nighttime and daytime was more pronounced in bandwidth $B 2$, with lowest values between midnight and 4:00 am $(102.1 \pm 0.1 \mathrm{~dB}$ re $1 \mu \mathrm{Pa})$ and highest values between 10:00 am and 4:00 pm $(109.1 \pm 1.4 \mathrm{~dB}$ re $1 \mu \mathrm{Pa})$. Dispersion around the mean (not shown) was not evenly distributed over the diel cycle. The diel pattern of SPL in $B 2$ bandwidth was strongly correlated $(r=0.67, p<0.001)$ with the average diel pattern of the summer traffic during the whale-watching season, from the analysis of Chion et al. (2010) for 2006, which shows daytime peaks in the number of boats in Saguenay mouth due to tour schedule. The mean noise level tends to peak when the number of boats increases 

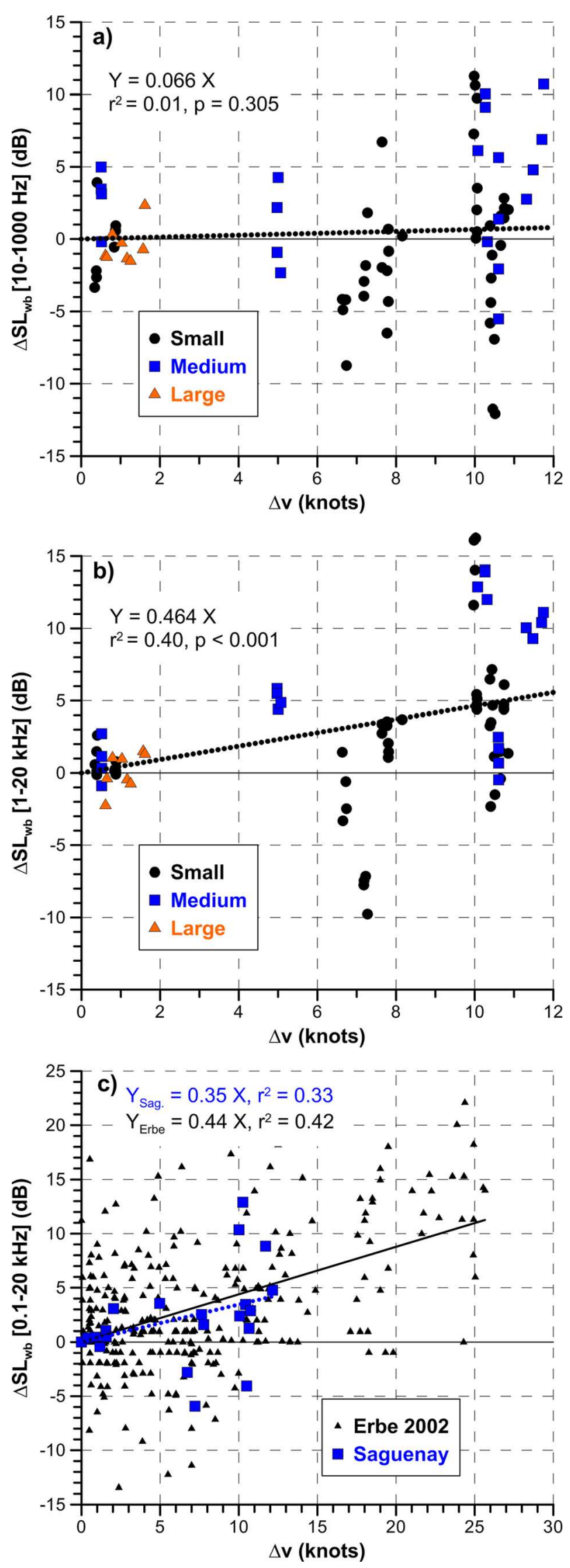

FIG. 4. (Color online) $\Delta \mathrm{SL}_{\mathrm{wb}}$ difference as function of speed increment $(\Delta v)$ between $\sim 10-15 \mathrm{kn}$ to $26 \mathrm{kn}$ per vessel category, separately for the (a) 0.01-1 kHz bandwidth, (b) the 1-20 kHz bandwidth from hydrophones 3 and 4 , and (c) comparison of the $0.01-20 \mathrm{kHz}$ bandwidth from hydrophone no. 4 with Erbe (2002).

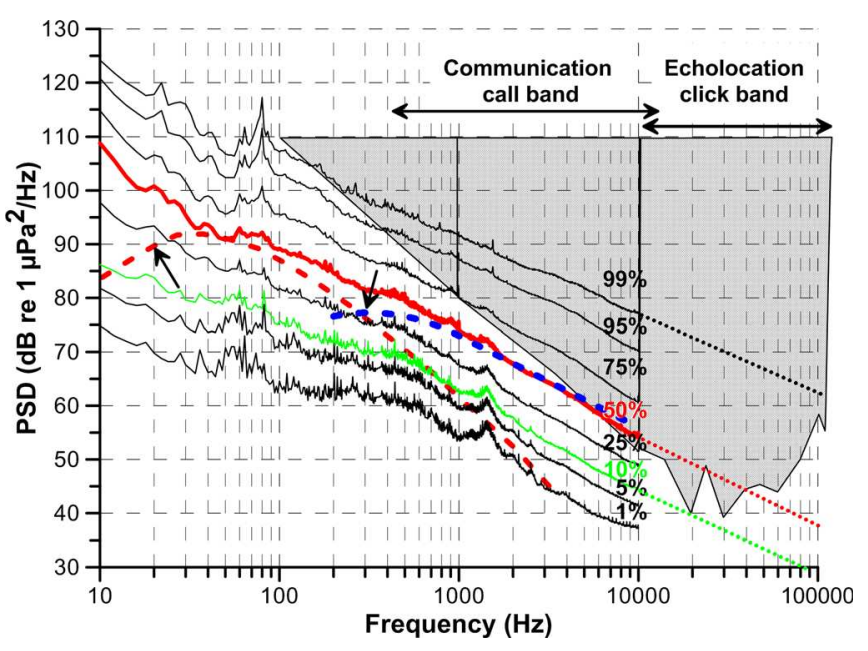

FIG. 5. (Color online) Percentiles of the cdf of measured noise PSD over the $[10 \mathrm{~Hz}-10 \mathrm{kHz}]$ band during the recording period; the 10 th percentile corresponds to the estimated natural ambient levels. The slopes of the median, 99th and 10th percentiles are extended to the [10-100 kHz] band from a linear fit to [5-10 kHz] frequencies. Overimposed are Wenz's reference curves for heavy traffic $<3 \mathrm{kHz}$ and for $40 \mathrm{kn}$ wind $>200 \mathrm{~Hz}$ (arrow pointed bold dotted lines), and beluga audible levels (shaded area) from the 1-s.d. lower bound of the composite audiogram envelope of Finneran et al. (2005), extended to $100 \mathrm{~Hz}$ with a slope of $-30 \mathrm{~dB}$ per decade from Erbe (2002).

(i.e., arrivals) or decreases (i.e., departures); the correlation slightly increases $(r=0.73)$ when the traffic series is shifted by $+1 \mathrm{~h}$.

High-resolution SPL series of one representative day shows the high small-scale variability $(30-35 \mathrm{~dB})$ in the bandwidth $B 2$ related to the frequent ferry transits between Tadoussac and Baie-Sainte-Catherine (Fig. 8). The frequency of occurrence of the oscillations is the crossing rhythm of the ferries (Table I). The smoothed series clearly reflects the general day-night trend depicted by the monthly

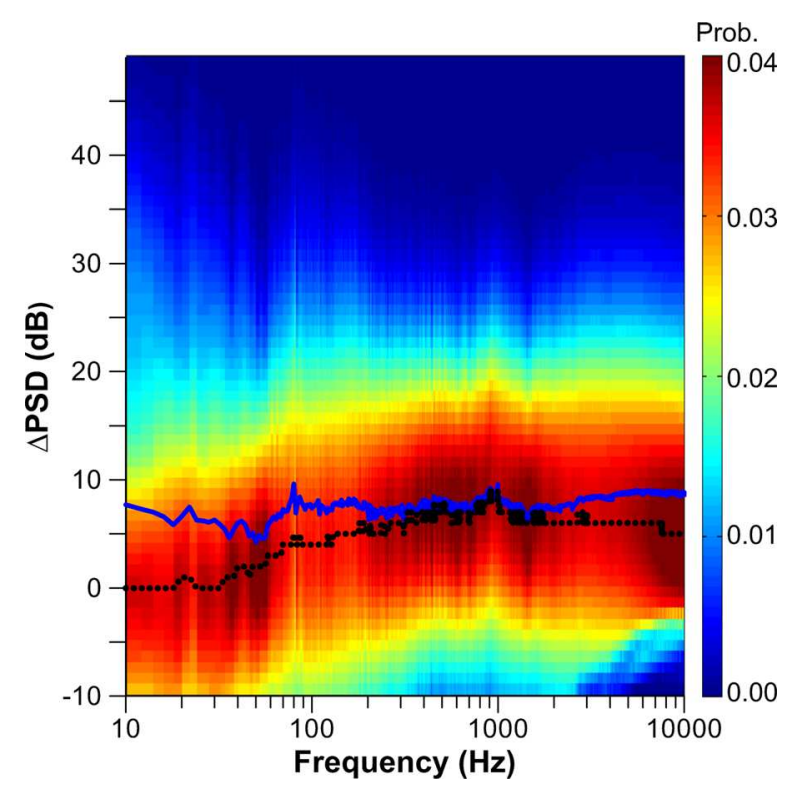

FIG. 6. (Color online) Probability that daytime noise differs from nighttime noise by the number of $\mathrm{dB}$ indicated by the ordinate axis, for frequencies from 10 to $10000 \mathrm{~Hz}$. Median difference with $1-\mathrm{dB}$ resolution (dashed line); mean difference (continuous bold line). 


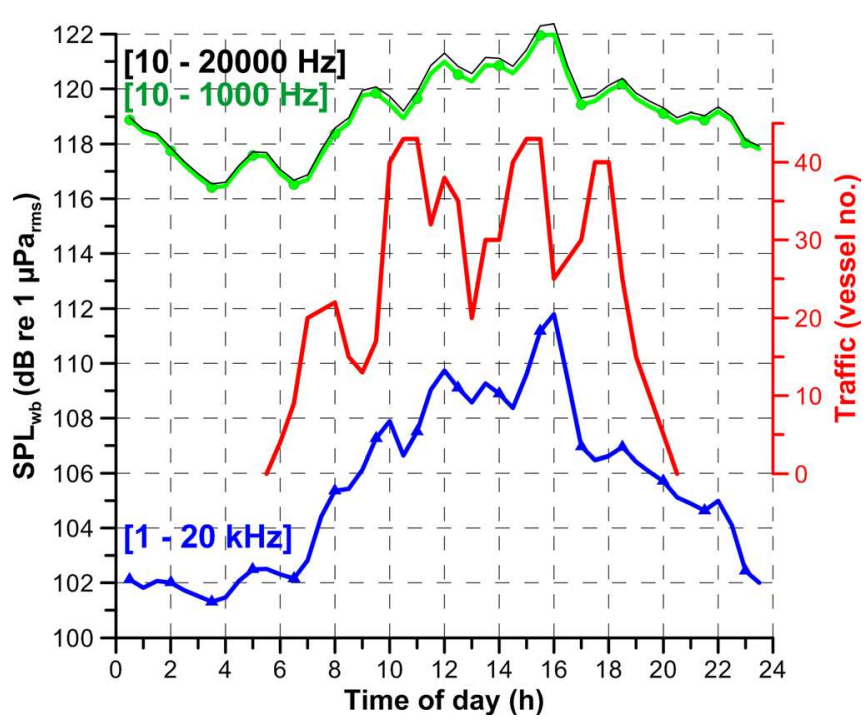

FIG. 7. (Color online) Mean broadband SPL over the diel cycle for the low(dotted line) and high-frequency (triangle line) bands separately and pooled (thin upper line) during the recording period and the daytime traffic statistics from Chion et al. (2010) (middle line).

average with several local maxima. The magnitude of the SPL oscillations due to transiting ferries has been estimated by computing the absolute difference between instantaneous and smoothed SPLs series and taking its 95th cdf percentile. This gives $12 \mathrm{~dB}$, which corresponds to oscillations ( $\left.\Delta_{\text {ferry }}\right)$ of $24 \mathrm{~dB}$. From the SPL time-series, the mean "acoustic" duration of ferry transits were $7 \mathrm{~min} 32 \mathrm{~s} \pm 2 \min (n=32)$.

\section{Contributors to local noise and beluga call masking}

The above results allow assessing the contribution of the different sources to the diel change in underwater noise in Saguenay Fjord mouth in the bandwidth $B 2$ used by beluga for communication (Fig. 9, Table I). First, for estimating the natural background noise level, shipping noise from the ferries and the whale watching fleet must be removed from

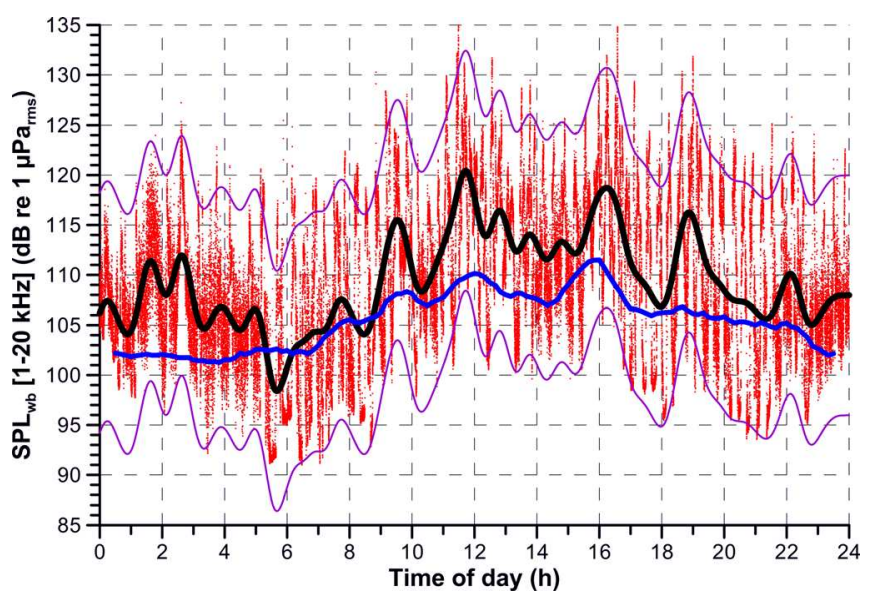

FIG. 8. (Color online) High-resolution $\mathrm{SPL}_{\mathrm{wb}}[1-20 \mathrm{kHz}$ ] for 7 June 2010 (dots) with its smoothed low-pass version (Butterworth filter, order 4, cutoff frequency $=1 / 3600 \mathrm{~Hz}$ ) (middle bold line), the $\pm 12 \mathrm{~dB}$ estimated magnitude of the fast oscillations around the low-pass series due to ferry transits (thin lines) and the monthly average (lower bold line).

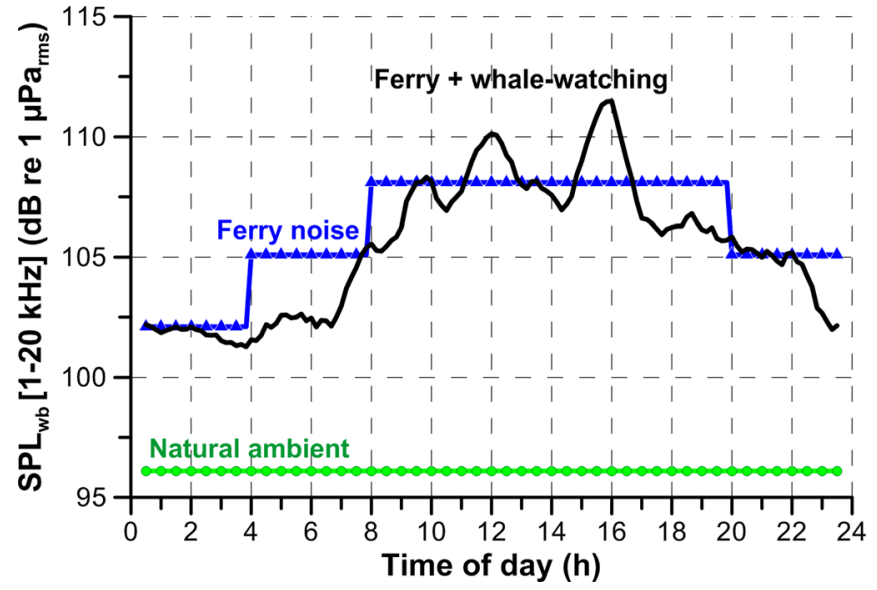

FIG. 9. (Color online) $\mathrm{SPL}_{\mathrm{wb}}[1-20 \mathrm{kHz}]$ diel series by source: natural floor level (dotted line), $\mathrm{SPL}_{\mathrm{wb}}$ with the addition ferry hourly mean level (triangle line), and total $\mathrm{SPL}_{\mathrm{wb}}$ including the whale-watching fleet (upper line).

the noise measurements. The lowest shipping activity in Saguenay mouth occurs during night, when only one ferry serves both sides every hour between midnight and 4:00 am. The average of the $\mathrm{SPL}_{\mathrm{wb}}[1-20 \mathrm{kHz}]$ estimates was then $102.1 \mathrm{~dB}$ re $1 \mu \mathrm{Pa}$. To get the average natural ambient noise level with no anthropogenic contribution $\left(\mathrm{SPL}_{\text {nature }}[1-20\right.$ $\mathrm{kHz}]$ ), the ferry contribution $\left(\Delta_{\text {ferry }}\right)$ must be withdrawn for the proportion of the hour, $w[0.126 \mathrm{~h}=(7+32 / 60) / 60]$, one crossing takes, multiplied by the crossing rate $(t r$ in $\left.\mathrm{h}^{-1}\right) . \mathrm{SPL}_{\text {nature }}[1-20 \mathrm{kHz}]$ is thus

$$
\mathrm{SPL}_{\text {nature }}[1-20 \mathrm{kHz}]=102.1 \mathrm{~dB}-t r \cdot \mathrm{w} \cdot \Delta_{\text {ferry }},
$$

where $t r=2 \mathrm{~h}^{-1}$.

Its solution produces $\mathrm{SPL}_{\text {nature }}[1-20 \mathrm{kHz}]=96.1 \mathrm{~dB}$ re $1 \mu \mathrm{Pa}$. This level corresponds to the 9.4th percentile of the cdf of SPL $_{\mathrm{wb}}[1-20 \mathrm{kHz}]$.

Using the same reasoning, and adding $3 \mathrm{~dB}$ [i.e., 10 $\left.\log _{10}(2)\right]$ when two ferries are simultaneously crossing, the average $\mathrm{SPL}_{\mathrm{wb}}[1-20 \mathrm{kHz}]$ can be estimated for the other levels of traffic of the daily schedule. These estimates are 105.1 $\mathrm{dB}$ re $1 \mu \mathrm{Pa}$ for 4:00 am-8:00 am $(t r=3, n=1), 108.1 \mathrm{~dB}$ re $1 \mu \mathrm{Pa}$ for 8:00 am-8:00 pm $(t r=3, n=2)$. In midsummer when a third ferry is added, the estimate is $114.1 \mathrm{~dB}$ re $1 \mu \mathrm{Pa}(t r=5, n=3)$.

The measured $\mathrm{SPL}_{\mathrm{wb}}[1-20 \mathrm{kHz}]$ indicates that the whale-watching fleet noise added up to $5.6 \mathrm{~dB}$ during peak hours over the observation period (Table I, Fig. 9). A few dB higher contribution is expected during the tourism peak season, in proportion with $10 \log _{10}$ (relative increment of the whale-watching tours). Pleasure craft traffic is also maximal at this time, and likely adds more noise.

To assess the degree of whale call masking, we take into account that natural conditions are reached at the 9.4th percentile of the cdf of the noise levels. Using the method of Sec. II C 3, the cdf of the increment in noise spectral level relative to natural conditions, $\triangle \mathrm{NL}$, and the corresponding cdf of $\mathrm{RRF}_{\mathrm{PSD}}$, were computed (Fig. 10). For frequencies below $300 \mathrm{~Hz}, \Delta \mathrm{NL}$ decreases with frequency with a median of $23 \mathrm{~dB}$ at $10 \mathrm{~Hz}$ and $12 \mathrm{~dB}$ at $300 \mathrm{~Hz}$ [Fig. 10(a)]. Above $300 \mathrm{~Hz}, \Delta \mathrm{NL}$ is fairly constant vs frequency, within a $\pm 2 \mathrm{~dB}$ 

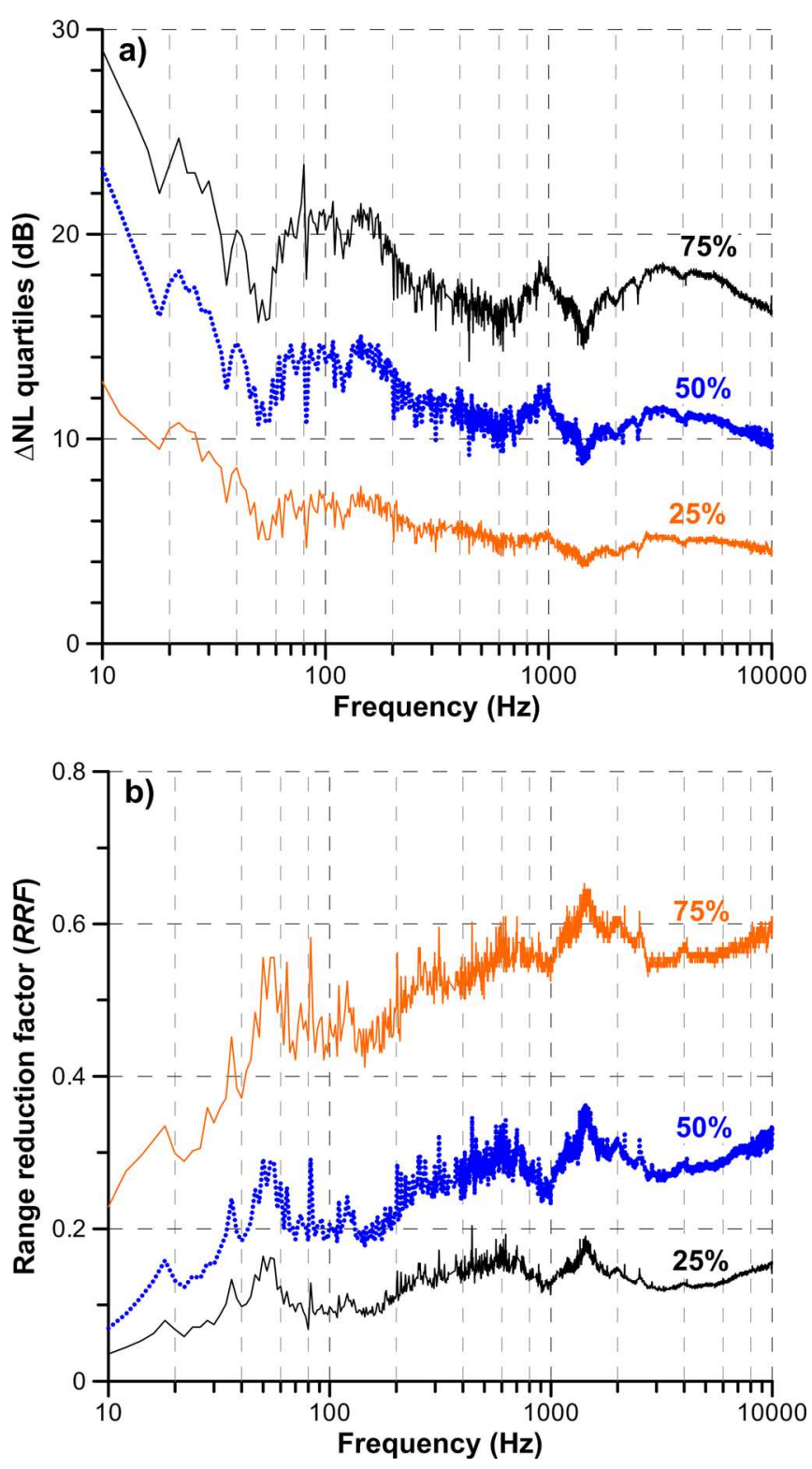

FIG. 10. (Color online) Saguenay Fjord mouth noise excess and RRF relative to natural conditions (a) cdf quartiles of noise level increments relative to natural ambient noise, $\Delta \mathrm{NL}$, as a function of acoustic frequency; these $\Delta \mathrm{NL}$ are exceeded $75 \%$ of the time for the first quartile, $50 \%$ for the median, and $25 \%$ of the time for the third quartile, and (b) the corresponding range reduction factor, i.e., the percentage of time the range is below the given ratios relative to natural conditions.

envelope. At $2.5 \mathrm{kHz}$, the center of the main frequency band of beluga calls (Bédard and Simard, 2006; Belikov and Bel'kovich, 2006), the noise increment relative to natural conditions is below $6 \mathrm{~dB}$ one quarter of the time, below 12 $\mathrm{dB}$ half of the time, and below $18 \mathrm{~dB}$ three quarters of the time.

The frequency dependence of the RRF $\mathrm{PSD}_{\mathrm{P}}$ mirrors the

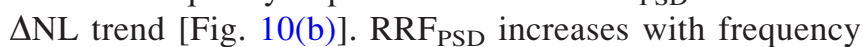
below $300 \mathrm{~Hz}$ and remains fairly constant above $300 \mathrm{~Hz}$. A quarter of the time, a $2.5-\mathrm{kHz}$ call would be masked at less than $15 \%$ of its range under natural conditions; half of the time, masking would occur at less than $30 \%$ of that range, and three quarter of the time it would be at less than $55 \%$ of that range. Again, these simple estimates do not take into account any behavioral or auditory responses from the emitting and the receiving animals.

\section{DISCUSSION}

\section{A. Soundscape characteristics and whale-watching fleet SLs}

\section{Whale-watching fleet SLS}

The whale-watching fleet SSL measured in this study are coherent with similar measurements conducted in other areas (Erbe, 2002; Kipple and Gabriele, 2003, 2004). At frequencies below $1 \mathrm{kHz}$, the SSL envelope ranges from lowSSL fishing vessel class up to the intermediate-SSL merchant ship and tanker classes from RANDI model outputs (Richardson et al., 1995; NRC, 2003) (Fig. 2). The median SSL of our three vessel categories are ordered as expected, with the large vessels being noisier than medium ones and the smaller ones the less noisy. These observations are in agreement with other field studies or modeling results (Urick, 1983; Wales and Heitmeyer, 2002; NRC, 2003; Kipple and Gabriele, 2004). However, the SSL variability follows the opposite trend, with the small vessel class being the most variable and the large vessel one the less variable. At $1.2 \mathrm{kHz}$, the s.d. of the large vessel class SSL is $2.5 \mathrm{~dB}$, which is consistent with the value of $3 \mathrm{~dB}$ estimated from a large collection of merchant ships studied by Wales and Heitmeyer (2002). For the small vessel class, which is made of visually similar boats, this same s.d. reaches $7.5 \mathrm{~dB}$. This large variability indicates that there is room for significant improvement in the overall noise imprint from this part of the fleet, by making the noisiest boats as silent as the most silent ones, either by mechanical upgrading or through fleet composition management.

SL dependence on vessel speed was not obvious from our data. Expecting that the effect of speed on ship noise might be frequency-dependent, we separately analyzed the low- and high-frequency bands. For the low-frequency band $B 1$, the linear regression failed to evidence any significant effect of speed increment on $\mathrm{SL}_{\mathrm{wb}}$ increment, within our window of speed increments above $10 \mathrm{kn}$. The noise level increased with speed for some vessels but decreased for the others. This may be related to the fact that the ships are tuned for an optimal cruising speed, and, during our experiment from $10 \mathrm{kn}$ to $25 \mathrm{kn}$, some of them improved their noise radiation performance by approaching their optimal speed and vice versa for the others. For the high-frequency band, from 1 to $20 \mathrm{kHz}$, a significant relation of $\Delta \mathrm{SL}_{\mathrm{wb}}$ with vessel speed increment above $10 \mathrm{kn}$ was observed, with a mean rate of $0.46 \mathrm{~dB}$ per incremental knot. Positive relations of radiated noise levels with vessel speed were also observed in other studies: $1.5-2 \mathrm{~dB}$ per $\mathrm{kn}[30 \mathrm{~Hz}-10 \mathrm{kHz}]$ for World War II navy ships (Urick, 1983), $2.0 \mathrm{~dB}$ per kn [120 Hz-5 kHz] from 5 to $12 \mathrm{kn}$ for a $40-\mathrm{m}$ research vessel in a British Columbia fjord (Trevorrow et al., 2008). Our rate is lower than the previous ones but close to Erbe (2002). The influence of speed increment on $\Delta \mathrm{SL}_{\mathrm{wb}}$ was weak and highly variable, as other studies also noted (Heitmeyer et al., 2003). A speed reduction from $25 \mathrm{kn}$ to $15 \mathrm{kn}$ could perhaps decrease the average noise 
level introduced by the fleet by $4.6 \mathrm{~dB}$. However, given the observed very large variability among the vessels of the fleet, the actual benefit of such a possible management approach could as well be negative depending on the fleet composition, since some vessels were more silent at high speeds than at low ones. Besides, the possible maximum benefit of such a speed reduction is low compared to the $29 \mathrm{~dB}$ range of $\mathrm{SL}_{\mathrm{wb}}$ of the small vessel class [Figs. 4(a) and 4(b)], where the noise reduction potential is much higher.

\section{Soundscape characteristics}

Anthropogenic sources make the Saguenay Fjord mouth a noisy environment for marine life. Natural ambient noise was estimated to correspond to the 9.4th percentile of the spectrum distribution (Fig. 5). The low-frequency natural noise spectra around $60 \mathrm{~Hz}$ correspond to levels predicted by Wenz (1962) for a traffic index of 5. Since shipping noise from local traffic in the Saguenay mouth at nighttime used to estimate the natural ambient noise has been removed, this suggests possible contributions from St. Lawrence shipping to the sound budget of Saguenay mouth. Recent acoustic measurements made in the 20-m deep narrow channel connecting the fjord to the St. Lawrence over the sill complex (Simard, unpublished data) indicate that transiting merchant ships on the St. Lawrence Seaway are indeed detectable. Traffic from the 10-km distant St. Lawrence shipping route ( $\sim 20$ ships per day) is therefore contributing within a narrow time-space window during transits. For higher frequencies, from $1 \mathrm{~Hz}$ to $10 \mathrm{kHz}$, natural noise spectrum is exactly that predicted by Wenz (1962) for a wind speed of $15 \mathrm{kn}$. The average wind speed observed during the 5-week recording period was $12.4 \pm 6.8 \mathrm{kn}$, and our natural noise spectrum exceeds Wenz's predictions by only $1.8 \mathrm{~dB}$. Slight excess of ambient noise measurements over Wenz's predictions have been reported for coastal environments by several studies (Ramji et al., 2008). This close agreement between the estimated natural ambient noise level and Wenz's predictions corrected for coastal areas corroborate our selection of the 9.4th percentile of the noise cdf to define maximal levels for natural ambient noise in our study area, which is twice the percentile value proposed by Clark et al. (2009) for the Stellwagen Bank area. Additional support for this choice comes from the fact that natural ambient noise has likely limited the auditory threshold of marine mammals (Richardson et al., 1995). Extending the 10th percentile of noise PSD to the frequency range of beluga maximal sensitivity exactly corresponds to the audiogram lower threshold (Fig. 5).

Noise levels in the studied area exceed the average natural ambient level $90 \%$ of the time. Below $200 \mathrm{~Hz}$ the median spectral level reaches Wenz's (1962) reference level for the highest traffic index (Fig. 5). At higher frequencies, it corresponds to Wenz's reference level for surface noise from 40$\mathrm{kn}$ winds (Fig. 5). The slope of noise level decrease with frequency in agreement with both Wenz's reference levels for wind dominated surface noise $(-17 \mathrm{~dB}$ per decade) and with the measured SSL from the local fleet. This suggests that noise excess relative to natural conditions in Saguenay mouth is essentially due to vessels traffic at both low and high frequencies, since such strong wind conditions are exceptional. The clear correlation of the diel pattern of noise level with the traffic in Saguenay mouth also supports this conclusion (Fig. 7). On average, spectral noise levels between $10 \mathrm{~Hz}$ and $10 \mathrm{kHz}$ were $8.4 \mathrm{~dB}$ higher in daytime than at nighttime.

The present Saguenay mouth noise budget was built with recordings from hydrophone no. 4 of our coastal array [Fig. 1(a)] because of its closer location to the beluga core distribution center [Fig. 1(b)], making it the best place for conservative impact assessments. Hydrophone no. 4 is on average $1.34 \mathrm{~km}$ away from the ferry paths [Fig. 1(c)] and is located near the routes followed by the whale-watching fleet to bridge Tadoussac with Baie Sainte-Catherine near Pointe Noire [Fig. 1(d)]. This specific location imposes a particular partition of the noise budget. To forecast the noise budget in another location of the Saguenay mouth, simulation modeling is needed. Present results on vessel SSL, natural noise level, and ferry noise provide realistic entries for different impacts assessment tools (Erbe and Farmer, 2000a; Frankel et al., 2002; Gisiner et al., 2006).

Results evidence the need to divide the full bandwidth $[10 \mathrm{~Hz}, 20 \mathrm{kHz}]$ into at least the two adjacent bands $B 1$ and $B 2$ since the main features of the noise budget (e.g., relationships between vessel SL and speed, and between NL and traffic schedule) were clearly visible in the highest band but not in the lowest band. When the full bandwidth is considered as a whole, the loud contribution of $B 1$ smears any feature visible on $B 2$.

\section{B. Masking impact on beluga communication and echolocation}

Beluga hearing is specialized in mid frequencies. Its U-shaped audiogram reaches a maximum sensitivity between 20 and $60 \mathrm{kHz}$ (Erbe, 2002; Finneran et al., 2005) (Fig. 5). The detection threshold is $\sim 95 \pm 13 \mathrm{~dB}$ re $1 \mu \mathrm{Pa}$ at $1 \mathrm{kHz}$, $60 \pm 5 \mathrm{~dB}$ re $1 \mu \mathrm{Pa}$ at $10 \mathrm{kHz}$, giving a slope of $\sim-35 \mathrm{~dB}$ per decade (Finneran et al., 2005), 2 times higher than the measured decreasing local noise slope with frequency. The minimum is reached around $30 \mathrm{kHz}$ at $52 \pm 14 \mathrm{~dB}$ re $1 \mu \mathrm{Pa}$.

Above $\sim 0.2 \mathrm{kHz}$, an increasing fraction of the measured underwater noise in Saguenay mouth is within the beluga hearing sensitivity range (Fig. 5). The fraction reaches a maximum of about $\sim 60 \%$ at $10 \mathrm{kHz}$, which is likely extending up to $\sim 40 \mathrm{kHz}$ before decreasing to zero at $\sim 110 \mathrm{kHz}$. Both the communication and echolocation bands in Saguenay mouth are therefore significantly affected by anthropogenic noise.

The effects of anthropogenic noise on marine mammals are a function of sound intensity, frequency, duration, acuteness, and repetitiveness (Southall et al., 2007). The type of effects and their spatial extent co-vary along a gradient ranging from injury and hearing losses at small scales, to masking, behavioral responsiveness, and threshold of audibility at the other end of the continuum (Richardson et al., 1995). Since the risk of physical damage to cetacean inner ear is mostly associated to sudden high-intensity sound pulses 
[ $>230 \mathrm{~dB}$ re $1 \mu \mathrm{Pa}_{\mathrm{p}}$ (Southall et al., 2007)], this kind of injury risk is unlikely for shipping noise and is irrelevant here. Longer-duration signals, such as propeller cavitation spikes, may trigger discomfort, but this rather subjective criterion is difficult to assess. Visual observations of the reaction distance to approaching ferries indicate that it could be as low as $100 \mathrm{~m}$, which corresponds to a propagation loss of $40 \mathrm{~dB}$ relative to SSL at $1 \mathrm{~m}$. Noise level at that distance from large vessels would then correspond to $\sim 100 \pm 5 \mathrm{~dB}$ re $1 \mu \mathrm{Pa}^{2} \mathrm{~Hz}^{-1}$ at $1 \mathrm{kHz}$ and $\sim 80 \pm 5 \mathrm{~dB}$ re $1 \mu \mathrm{Pa}^{2} \mathrm{~Hz}^{-1}$ at $40 \mathrm{kHz}$ (Fig. 3), which is $15-30 \mathrm{~dB}$ above the audiogram (Fig. 5).

High risk of permanent shift in hearing threshold (PTS) for mid-frequency specialized cetaceans exposed to nonpulse noise is estimated to occur at a sound exposure level $\left(\mathrm{SEL}=\mathrm{SPL}+10 \log _{10}(T)\right.$, where $T$ is the period in $\left.\mathrm{s}\right)$ higher than $215 \mathrm{~dB}$ re $1 \mu \mathrm{Pa}^{2} \mathrm{~s}_{(\mathrm{Mmf})}{ }^{3}$ over a $24 \mathrm{~h}$ period (Southall et al., 2007). Such an exposure level is unlikely to be reached in the study area. An improbable animal continuously exposed to the highest measured daytime broadband noise of $\sim 112 \mathrm{~dB}$ re $1 \mu \mathrm{Pa}$ above $1 \mathrm{kHz}$ [lower limit of Mmf weighting curve of Southall et al. 2007), Fig. 7] would get a $\mathrm{SEL}_{24 \mathrm{~h}}$ of $\sim 161 \mathrm{~dB}$ re $1 \mu \mathrm{Pa}^{2} \mathrm{~s}_{(\mathrm{Mmf})}$. Therefore the risk of PTS from short-term exposure to local shipping noise can be considered very low.

Finneran et al. (2010) observed a marked growth of temporary threshold shift (TTS) after exposure to $3 \mathrm{kHz}$ noise with SEL exceeding $\sim 190-195 \mathrm{~dB}$ re $1 \mu \mathrm{Pa}^{2} \mathrm{~s}$ in bottlenose dolphins, and little or no TTS at lower levels. Exposing the same species to a $4-8 \mathrm{kHz}$ octave band noise resulted in similar SEL values for inducing TTS at frequencies varying from 5.5 to $22.5 \mathrm{kHz}$ (Mooney et al., 2009). A SEL criterion of $190 \mathrm{~dB}$ re $1 \mu \mathrm{Pa}^{2} \mathrm{~s}$ for TTS onset would also not be attained over a 24-h exposure to the highest observed broadband noise above $1 \mathrm{kHz}$ in Saguenay Fjord mouth. Erbe and Farmer (2000a) used a 1-octave noise level of $96 \mathrm{~dB}$ above the audiogram to estimate TTS based on the observation of Au et al. (1999) of a 12-18 dB TTS on bottlenose dolphin exposed to a $7.5-\mathrm{kHz}$ octave band noise for $30-50 \mathrm{~min}$. Integrating the 99th percentile of the cdf of measured noise PSD of Fig. 5 over a 1-octave bandwidth never exceeds the conservative beluga composite audiogram of Fig. 5 by more than $70 \mathrm{~dB}$. Therefore, TTS of beluga hearing due to local shipping noise is also unlikely based on that criterion. At closer ranges from the ferry than our measurements, the risk of TTS is also low because the avoidance reaction at a distance of $100 \mathrm{~m}$ keeps the 1-octave noise level below $96 \mathrm{~dB}$ above the audiogram.

The main and immediate impact of the nonpulse shipping noise characterizing the local soundscape is the masking of communication and echolocation signals, as well as of the acoustic scene. This latter carries a multi-scale continuum of information about diverse and dynamic physical and biological characteristics of the 3D habitat, continuously exploited by the animal for its survival. Efficient use of passive and active acoustics is essential to animals for achieving individual, group, and population level vital functions, such as feeding, reproduction, and surviving to predation and anthropogenic threats.
Masking occurs when the signal of interest cannot be effectively detected or recognized by the receiver (Clark et al., 2009). Erbe and Farmer examined masking of one beluga call, composed of six repeated phonemes with harmonics, by ice noise, two types of icebreaker noise, and artificial white noise with a captive animal, and a sound propagation model to assess the zones of impact around an icebreaker using Fletcher's (1940) equal-power assumption within critical bands of twelfth-octave (Erbe and Farmer, 1998, 2000a,b; Erbe, 2008). This approach is useful to assess the potential impact of anthropogenic noise, although masking is more complex than this simple energetic model (Finneran et al., 2002; Erbe, 2008; Clark et al., 2009; Trickey et al., 2010). Masking notably also depends on signal and noise time-frequency structures and hearing directivity besides SNRs of received levels. Using beluga critical ratios, $\mathrm{CR}$ (i.e., ratio of the energy of a pure tone to the noise in the masking band) as a function of frequency from Johnson et al. (1989) and twelfth-octave band noise cdf computed from Fig. 5, we can build a masking cdf plot showing the level-frequency areas of potential masking from given percentiles of observed noise cdf (Fig. 11). At the 99th percentile of the noise PSD, signals between 1 and $70 \mathrm{kHz}$ must exceed the audiogram by $10-25 \mathrm{~dB}$ to be detected according to the equal-power assumption [Fig. 11(b), 99\%-CR curve]. This corresponds to a significant fraction of both the communication and echolocation bands. Median noise level also has the potential to mask audible but weak signals between 4 and $40 \mathrm{kHz}$ [Fig. 11(b), 50\%-CR curve]. In this latter frequency bandwidth, the observed noise has therefore the potential to mask communication and echolocation for half of the time under the equal-power assumption [Fig. 11(b), area between the 99\%-CR and the 50\%-CR that exceeds the hearing threshold]. Masking could occur more than 50\% of the time in daytime, since lower noise levels occur at night. This, however, assumes no compensatory response by the animals.

A complementary way to estimate the impact of masking in a given habitat is by comparing the range at which a signal reaches its limit of detectability or interpretability under given noise conditions compared to natural noise conditions using the computed RRF, as proposed by NRC (2003) and used for relative communication space assessment (Clark et al., 2009). A reduction of potential communication ranges of usual beluga calls to less than $30 \%$ of their values under natural noise conditions for half of the time in Saguenay mouth indicates a significant change of the natural soundscape by shipping noise. To estimate the actual effects of such a reduction of beluga communication space, several unknowns on free-ranging beluga bioacoustics must first be resolved, especially the pdfs of their call SLs, their audiograms, and their detection thresholds for the different types of frequency modulated, amplitude modulated, and pulsed calls, as well as their level of use of long-distance communication.

Simple estimate of maximum communication range under natural noise conditions, assuming spherical spreading loss, a twelfth-octave SL of $160 \mathrm{~dB}$ re $1 \mu \mathrm{Pa}$ at $1 \mathrm{~m}$ for a 2.5 $\mathrm{kHz}$ central frequency call, and a $10 \mathrm{~dB}$ SNR detection 

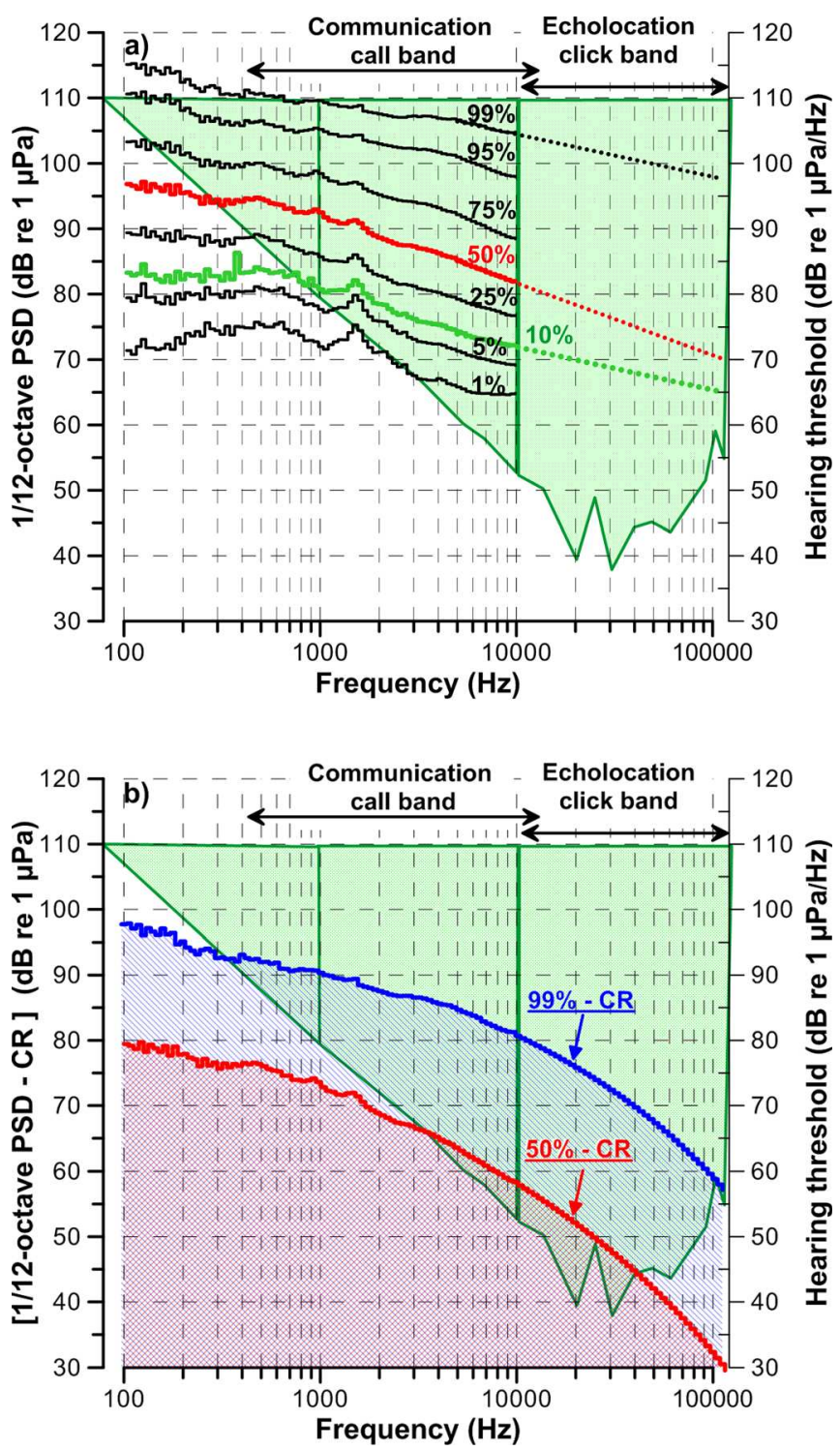

FIG. 11. (Color online) (a) Cdf of measured noise PSD as in Fig. 5 but for twelfth-octave bands, (b) level-frequency areas of masked signals corresponding to the 50th or 99th percentile of the measured noise cdf, based on the Fletcher's equal-power tonal masking model and beluga CR from Johnson et al. (1989). Signals with twelfth-octave levels smaller than the curves would be masked assuming no behavioral or auditory compensation. Beluga audible area (shaded background) as in Fig. 5.

threshold, give a range of $\sim 4.5 \mathrm{~km}$ to exceed twelfth-octave natural noise level by $10 \mathrm{~dB}$. Such a one-way communication range would cover the whole Saguenay mouth area. Under present shipping noise conditions, this range is lower than $1.5 \mathrm{~km}$, the fjord width, $50 \%$ of the time, and lower than $0.6 \mathrm{~km}, 25 \%$ of the time. Again, these time fractions are higher during daytime because of the day and night differences in noise levels. It is therefore likely that the communications between distant beluga pods or individuals scattered in Saguenay mouth are ineffective during high-traffic hours. Shifting the calls to higher frequencies (Lesage et al., 1999) cannot be used here to compensate the masking since the RRF does not improve over the whole communication band [Fig. 10(b)]. A Lombard response (Scheifele et al., 2005; Holt et al., 2009) would, however, be effective. Raising the SL by $20 \mathrm{~dB}$ would increase the propagation range by a factor of 10. Other possible masking compensations include directional hearing, exploiting duration, time, and frequency contents of both the noise and the call, and call repetition (Lesage et al., 1999; Foote et al., 2004; Branstetter and Finneran, 2008; Erbe, 2008).

The echolocation range could be strongly reduced by local shipping noise relative to natural noise conditions, since two-way propagation loss from the animal to the target must be taken into account in computing RRF [Eq. (2)]. This masking can, however, be partly compensated by the high directivity (32 dB) of beluga biosonar (Au et al., 1987). Simple estimates indicate that possible ranges of echolocation of different targets (small fish, fish school, boundary interfaces) could be reduced to $\sim 80 \%$ of their range under natural noise conditions under median noise levels, and to $\sim 20 \%$ under the highest (99th) percentile of the observed noise. The short inter click intervals $(22 \pm 33 \mathrm{~ms})$ of non-buzz clicks recorded in Saguenay Fjord mouth however do not support frequent long-range echolocation, most echo-ranging being rather on the order of a few tenths of meters (Roy et al., 2010). Nevertheless, the above simple estimates indicate that shipping noise can affect the performance of beluga search and inspection of a common prey with its biosonar in Saguenay Fjord mouth. Compensation by frequency shifting, SL increases and click sequence encoding (Au et al., 1985; Lesage et al., 1999; Au and Benoit-Bird, 2003; Scheifele et al., 2005; Tyack, 2008; Roy et al., 2010), are among possibilities to reduce the noise impact to allow exploiting areas of high interest that are strongly affected by human activities. The cost of such adaptations for the individuals and the population, and the limits to resilience before habitat desertion happens, remain to be evaluated.

Further research should include modeling tools, parameterized with our ground truth entries, to (i) simulate the noise budget at any 3D location in the Saguenay mouth, (ii) explore effects of the composition of the whale-watching fleet and its scheduling to minimize adverse impacts on beluga communication and echolocation, and (iii) propose optimal SL characteristics for ferries and whale-watching fleet vessels. Special efforts should be directed to the identification of the sources of SL dispersion of small vessels. The noise budget should be completed in the high-frequency echolocation band. The impact on echolocation and the actual compensation responses by animals needs further attention. Finally, similar soundscape budgets and characterizations based on significant measurement efforts, supplemented with beluga frequentation patterns, should be conducted in the other highly frequented areas to contribute to the evaluation of the global exposure of the endangered St. Lawrence beluga population.

\section{CONCLUSION}

The underwater soundscape of a busy shipping area of the SSLMP highly frequented by belugas has been characterized from a 40 days continuous measurement with a 4-hydrophone cabled array deployed in the frequentation core. The local conditions allowed estimating the contribution of the different sources and determining the level of natural 
ambient noise as it corresponds to the 9.4th percentile of the observed noise pdf, which was consistent with noise level predictions for the observed average wind speed. Natural ambient noise levels mainly occur at night. On average, observed noise between $10 \mathrm{~Hz}$ and $10 \mathrm{kHz}$ was $8.4 \mathrm{~dB}$ higher in daytime than at nighttime. During daytime, the noise time series correlates with the local traffic. Ferries increase the natural ambient levels by $6.2 \mathrm{~dB}$ at night, and $8 \mathrm{~dB}$ or $11 \mathrm{~dB}$ in daytime. The whale-watching fleet adds up $\sim 6 \mathrm{~dB}$ over ferries noise at times of departures or arrivals of their trips.

The average SL and SSL of the whale-watching vessels slightly increased with vessel size whereas dispersion around the average SSL followed the opposite trend. The smallest class (mainly rigid-hull inflatable boats) was highly dispersed and showed a $29 \mathrm{~dB}$ SSL envelope. A $0.5 \mathrm{~dB}$ increase of SL [1-20 kHz] per incremental knot between 10 and 25 $\mathrm{kn}$ speed was estimated, but it only explained $40 \%$ of the SL variance.

The chronic anthropogenic noise of this area is dominated by $<1 \mathrm{kHz}$ noise, with hourly mean reaching $122 \mathrm{~dB}$ re $1 \mu \mathrm{Pa}$. Above $1 \mathrm{kHz}$, the hourly mean reaches $112 \mathrm{~dB}$, and peaks occasionally exceed $130 \mathrm{~dB}$ re $1 \mu \mathrm{Pa}$. A large part of the noise is audible by belugas over both their communication and echolocation bands. The risk of injury from this type of nonpulse noise is low. The main effect of this anthropogenic noise is its potential of masking the communication and echolocation. Assuming no compensation response from the animals, this possibility would occur $50 \%$ of the time on average, increasing during daytime and decreasing during nighttime. Half of the time, the potential communication range is reduced to $30 \%$ of what it would be under natural noise conditions, hence potentially limiting basin-wide communications between individuals or pods. At the upper noise levels, the risk of affecting echolocation efficiency cannot be excluded. Among compensations possibilities, frequency switching alone does not appear to be efficient for the noise encountered in this area.

\section{ACKNOWLEDGMENTS}

This work has been funded by Fisheries and Oceans Canada, NSERC Discovery grant to Y.S., ISMER-UQAR Chair in underwater acoustics applied to ecosystem and marine mammals, and Europôle Mer research grant to C.G. We especially thank Benoit Dubeau and Manuela Conversano and other members of Parks Canada team at the SSLMP for their contributions to the project. The generous collaboration of the whale-watching fleet owners and captains was particularly appreciated. We also thank the crews of the CCGS Calanus II for their help with the deployment and recuperation of the hydrophone array. We are grateful to several students for their contribution to the success of field work. Thanks to the Defence Research and Development Canada group in Dartmouth for the calibration of the hydrophones.

\footnotetext{
${ }^{1}$ Sensu NRC (2003): "background din emanating from a myriad of unidentified sources."

${ }^{2}$ Errors presented in this paper are \pm s.d.

${ }^{3} \mathrm{Mmf}$ : Frequency weighting for mid-frequency cetaceans (most odontocetes) (cf. Southall et al., 2007).
}

Arveson, P. T., and Vendittis, D. J. (2000). "Radiated noise characteristics of a modern cargo ship,” J. Acoust. Soc. Am. 107, 118-129.

Au, W. W. L., and Benoit-Bird, K. J. (2003). "Automatic gain control in the echolocation system of dolphins," Nature 423, 861-863.

Au, W. W. L., Carder, D. A., Penner, R. H., and Scronce, B. L. (1985). "Demonstration of adaptation in beluga whale echolocation signals," J. Acoust. Soc. Am. 77, 726-730.

Au, W. W. L., and Hastings, M. C. (2008). Principles of Marine Bioacoustics (Springer, New York), pp. 1-679.

$\mathrm{Au}$, W. W. L., Nachtigall, P. E., and Pawloski, J. L. (1999). “Temporary threshold shift in hearing induced by an octave band of continuous noise in the bottlenose dolphin," J. Acoust. Soc. Am. 106, 2251(A).

Au, W. L., Penner, R. H., and Turl, C. W. (1987). "Propagation of beluga echolocation signals," J. Acoust. Soc. Am. 82, 807-813.

Bédard, C., and Simard, Y. (2006). "Automated detection of white whale (Delphinapterus leucas) vocalizations in St. Lawrence estuary and occurrence pattern," Can. Acoust. 34, 84-85.

Belikov, R., and Bel'kovich, V. (2006). "High-pitched tonal signals of beluga whales (Delphinapterus leucas) in a summer assemblage off Solovetskii Island in the White Sea," Acoust. Phys. 52, 125-131.

Boyd, I., Frisk, G., Urban, E., Tyack, P., Ausubel, J., Seeyave, S., Cato, D., Southall, B., Weise, M., Andrew, R., Akamatsu, T., Dekeling, R., Erbe, C., Farmer, D., Gentry, R., Goss, T., Hawkins, A., Li, F., Metcalf, K., Miller, J., Moretti, D., Rodrigo, C., and Shinke, T. (2011). "An international quiet oceans experiment," Oceanography 24, 174-181.

Branstetter, B. K., and Finneran, J. J. (2008). "Comodulation masking release in bottlenose dolphins (Tursiops truncatus)," J. Acoust. Soc. Am. 124, 625-633.

Chion, C., Turgeon, S., Michaud, R., Landry, J.-A., and Parrott, L. (2010). "Portrait de la navigation dans le parc marin du Saguenay-Saint-Laurent: Caractérisation des activités sans prélèvement de ressources entre le 1er mai et le 31octobre 2007 (Shipping characteristics in Saguenay-St. Lawrence marine park)" (Parks Canada, Québec, Canada), pp. $1-86$.

Clark, C., Ellison, W. T., Southall, B. L., Hatch, L., Van Parijs, S., Frankel, A. S., and Ponirakis, D. (2009). "Acoustic masking in marine ecosystems: Intuitions, analysis, and implication," Mar. Ecol.: Prog. Ser. 395, 201-222.

Erbe, C. (2002). "Underwater noise of whale-watching boats and potential effects on killer whales (Orcinus orca), based on an acoustic impact model," Marine Mammal Sci. 18, 394-418.

Erbe, C. (2008). "Critical ratios of beluga whales (Delphinapterus leucas) and masked signal duration," J. Acoust. Soc. Am. 124, 2216-2223.

Erbe, C., and Farmer, D. M. (1998). "Masked hearing thresholds of a beluga whale (Delphinapterus leucas) in icebreaker noise," Deep-Sea Res., Part II 45, 1373-1388.

Erbe, C., and Farmer, D. M. (2000a). "A software model to estimate zones of impact on marine mammals around anthropogenic noise," J. Acoust. Soc. Am. 108, 1327-1331.

Erbe, C., and Farmer, D. M. (2000b). "Zones of impact around icebreakers affecting beluga whales in the Beaufort Sea," J. Acoust. Soc. Am. 108, $1332-1340$.

Finneran, J. J., Carder, D. A., Dear, R., Belting, T., McBain, J., Dalton, L., and Ridgway, S. H. (2005). "Pure tone audiograms and possible aminoglycoside-induced hearing loss in belugas (Delphinapterus leucas)," J. Acoust. Soc. Am. 117, 3936-3943.

Finneran, J. J., Carder, D. A., Schlundt, C. E., and Dear, R. L. (2010). "Growth and recovery of temporary threshold shift at $3 \mathrm{kHz}$ in bottlenose dolphins: Experimental data and mathematical models," J. Acoust. Soc. Am. 127, 3256-3266.

Finneran, J. J., Schlundt, C. E., Carder, D. A., and Ridgway, S. H. (2002). "Auditory filter shapes for the bottlenose dolphin (Tursiops truncatus) and the white whale (Delphinapterus leucas) derived with notched noise," J. Acoust. Soc. Am. 112, 322-328.

Fletcher, H. (1940). "Auditory patterns," Rev. Mod. Phys. 12, 47-61.

Foote, A. D., Osborne, R. W., and Hoelzel, A. R. (2004). "Whale-call response to masking boat noise," Nature $\mathbf{4 2 8}, 910$.

Frankel, A. S., Ellison, W. T., and Buchanan, J. (2002). "Application of the acoustic integration model (AIM) to predict and minimize environmental impacts," in Proceedings of IEEE Oceans 2002, Biloxi, MS, pp. $1438-1443$.

Gisiner, R., Harper, S., Livingston, E., and Simmen, J. (2006). "Effects of sound on the marine environment (ESME): An underwater noise risk model,” IEEE J. Ocean. Eng. 31, 4-7. 
Heitmeyer, R. M., Wales, S. C., and Pflug, L. A. (2003). "Shipping noise predictions: Capabilities and limitations," Mar. Technol. Soc. J. 37, 54-65.

Hildebrand, J. (2009). "Anthropogenic and natural sources of ambient noise in the ocean," Mar. Ecol.: Prog. Ser. 395, 5-20.

Holt, M. M., Noren, D. P., Veirs, V., Emmons, C. K., and Veirs, S. (2009). "Speaking up: Killer whales (Orcinus orca) increase their call amplitude in response to vessel noise," J. Acoust. Soc. Am. 125, EL27-EL32.

Jensen, F. H., Bejder, L., Wahlberg, M., Aguilar Soto, N., Johnson, M., and Madsen, P. T. (2009). "Vessel noise effects on delphinid communication," Mar. Ecol.: Prog. Ser. 395, 161-175.

Johnson, C. S., McManus, M. W., and Skaar, D. (1989). "Masked tonal hearing thresholds in the beluga whale," J. Acoust. Soc. Am. 85, 2651-2654.

Kipple, B., and Gabriele, C. (2003). "Glacier Bay watercraft noise," Naval Surface Warfare Center, Bremerton, WA, Technical Report NSWCCDE71-TR-2003/522, prepared for Glacier Bay National Park and Preserve, pp. 1-54.

Kipple, B., and Gabriele, C. (2004). "Glacier Bay watercraft noise-Noise characterization for tour, charter, private, and government vessels," Naval Surface Warfare Center, Bremerton, WA, Technical Report NSWCCDE71-TR-2004/545, prepared for Glacier Bay National Park and Preserve, pp. 1-47.

Lesage, V., Barrette, C., Kingsley, M. C. S., and Sjare, B. (1999). "The effect of vessel noise on the vocal behavior of belugas in the St. Lawrence River estuary, Canada," Marine Mammal Sci. 15, 65-84.

Lusseau, D., Bain, D. E., Williams, R., and Smith, J. C. (2009). "Vessel traffic disrupts the foraging behavior of southern resident killer whales Orcinus orca," Endang. Species Res. 6, 211-221.

Mitson, R. B. (1995). "Undervater noise of research vessels: Review and recommendations," ICES Coop. Res. Rep. No. 209, pp. 1-61.

Mooney, T. A., Nachtigall, P. E., Breese, M., Vlachos, S., and Au, W. W. (2009). "Predicting temporary threshold shifts in a bottlenose dolphin (Tursiops truncatus): The effects of noise level and duration," J. Acoust. Soc. Am. 125, 1816-1826.

NRC. (2003). Ocean Noise and Marine Mammals (National Academies, Washington, DC), pp. 1-192.

O'Connor, S., Campbell, R., Cortez, H., and Knowles, T. (2009). "Whale watching worldwide: Tourism numbers, expenditures and expanding economic benefits," Special report prepared by Economists at Large, International Fund for Animal Welfare, Yarmouth, MA, pp. 1-295.
Popper, A. N., and Hastings, M. C. (2009). "The effects of human-generated sound on fish," Integrative Zool. 2009, 43-52.

Ramji, S., Latha, G., Rajendran, V., and Ramakrishnan, S. (2008). "Wind dependence of ambient noise in shallow water of Bay of Bengal," Appl. Acoust. 69, 1294-1298.

Richardson, W. J., Greene, C. J., Malme, C., and Thomson, D. (1995). Marine Mammals and Noise (Academic, New York), pp. 1-576.

Roy, N., Simard, Y., and Gervaise, C. (2010). "3D tracking of foraging belugas from their clicks: Experiment from a coastal hydrophone array,” Appl. Acoust. 71, 1050-1056.

Scheifele, P. M., Andrew, S., Cooper, R. A., Darre, M., Musiek, F. E., and Max, L. (2005). "Indication of a Lombard vocal response in the St. Lawrence river beluga," J. Acoust. Soc. Am. 117, 1486-1492.

Simard, Y., Roy, N., and Gervaise, C. (2008). "Passive acoustic detection and localization of whales: Effects of shipping noise in Saguenay-St. Lawrence Marine Park," J. Acoust. Soc. Am 123, 4109-4117.

Simard, Y., Roy, N., Giard, S., Gervaise, C., Conversano, M., and Ménard, N. (2010). "Estimating whale density from their whistling activity: Example with St. Lawrence beluga," Appl. Acoust. 71, 1081-1086.

Southall, B. L., Bowles, A. E., Ellison, W. T., Finneran, J. J., Gentry, R. L., Greene, C. R., Jr., Kastak, D., Ketten, D. R., Miller, J. H., Nachtigall, P. E., Richardson, W. J., Thomas, J. A., and Tyack, P. L. (2007). "Marine mammal noise exposure criteria: Initial scientific recommendations," Aquat. Mamm. 33, 410-522.

Trevorrow, M. V., Vassiliev, B., and Vagle, S. (2008). "Directionality and maneuvering effects on a surface ship underwater acoustic signature," J. Acoust. Soc. Am. 124, 767-778.

Trickey, J. S., Branstetter, B. K., and Finneran, J. J. (2010). “Auditory masking of a $10 \mathrm{kHz}$ tone with environmental, comodulated, and Gaussian noise in bottlenose dolphins (Tursiops truncatus)," J. Acoust. Soc. Am. 128, 3799-3804.

Tyack, P. (2008). "Implications for marine mammals of large-scale changes in the marine acoustic environment," J. Mammol. 89, 549-558.

Urick, R. J. (1983). Principles of Underwater Sound, 3rd ed. (McGraw-Hill, New York), pp. 1-423.

Wales, S. C., and Heitmeyer, R. M. (2002). "An ensemble source spectra model for merchant ship-radiated noise," J. Acoust. Soc. Am. 111, 1211-1231.

Wenz, G. M. (1962). "Acoustic ambient noise in the ocean: Spectra and sources," J. Acoust. Soc. Am. 34, 1936-1956. 